\title{
Excessive Activation of Serotonin (5-HT) 1B Receptors Disrupts the Formation of Sensory Maps in Monoamine Oxidase A and 5-HT Transporter Knock-Out Mice
}

\author{
Nathalie Salichon, ${ }^{1}$ Patricia Gaspar, ${ }^{2}$ A. Louise Upton, ${ }^{2}$ Sandrine Picaud, ${ }^{1}$ Naïma Hanoun, ${ }^{3}$ Michel Hamon, ${ }^{3}$ \\ Edward De Maeyer, ${ }^{1}$ Dennis L. Murphy, ${ }^{4}$ Rainald Mössner, ${ }^{5}$ Klaus Peter Lesch, ${ }^{5}$ René Hen, ${ }^{6}$ and \\ Isabelle Seif ${ }^{1}$ \\ ${ }^{1}$ Centre National de la Recherche Scientifique, Unité Mixte de Recherche 146, Institut Curie, 91405 Orsay, France, \\ 2Institut National de la Santé et de la Recherche Médicale (INSERM) U106, Hôpital de la Pitié-Salpêtrière, 75651 Paris, \\ France, 3/NSERM U288, Hôpital de la Pitié-Salpêtrière, 75634 Paris, France, ${ }^{4}$ Laboratory of Clinical Science, The National \\ Institute of Mental Health, Bethesda, Maryland 20892, 5Department of Psychiatry and Psychotherapy, University of \\ Würzburg, 97080 Würzburg, Germany, and ${ }^{6}$ Center for Neurobiology and Behavior, Columbia University, New York, New \\ York 10032
}

Deficiency in the monoamine degradation enzyme monoamine oxidase $A(M A O A)$ or prenatal exposure to the monoamine uptake inhibitor cocaine alters behavior in humans and rodents, but the mechanisms are unclear. In MAOA knock-out mice, inhibiting serotonin synthesis during development can prevent abnormal segregation of axons in the retinogeniculate and somatosensory thalamocortical systems. To investigate this effect, we crossed MAOA knock-outs with mice lacking the serotonin transporter 5-HTT or the 5-HT1B receptor, two molecules present in developing sensory projections. Segregation was abnormal in 5-HTT knock-outs and MAOA/5-HTT double knock-outs but was normalized in MAOA/5-HT1B double knock-outs and MAOA/5-HTT/5-HT1B triple knock-outs. This demonstrates that the 5-HT1B receptor is a key factor in abnormal segregation of sensory projections and suggests that serotonergic drugs represent a risk for the development of these projections. We also found that the 5-HT1B receptor has an adverse developmental impact on beam-walking behavior in MAOA knock-outs. Finally, because the 5-HT1B receptor inhibits glutamate release, our results suggest that visual and somatosensory projections must release glutamate for proper segregation.

Key words: 5-HT ${ }_{1 B}$ receptor; monoamine oxidase; serotonin transporter; activity-dependent development; retinal projections; dorsal lateral geniculate nucleus; thalamocortical; barrel field
The processes underlying patterning of projections in the somatosensory and visual systems have been intensively studied for more than two decades with a widely held view that the formation of somatotopic maps does not depend on neural activity, whereas the formation of retinotopic maps does (O'Leary et al., 1994; Katz and Shatz, 1996; Feldman et al., 1999). Recently, a possible point of similarity between the two sensory systems has been provided by observations in monoamine oxidase A knock-out (MAOA KO) mice, showing that excess serotonin (5-HT) disrupts both the segregation of somatosensory thalamocortical afferents into whisker-specific domains and the segregation of retinogeniculate and retinotectal afferents into eye-specific domains (Cases et al., 1996; Upton et al., 1999). The period for 5-HT action corresponds to the period when incoming axons begin to establish synaptic interactions with target neurons and to elaborate a profuse branch-

\footnotetext{
Received Aug. 7, 2000; revised Oct. 12, 2000; accepted Nov. 2, 2000.

This work was supported by the European Commission (BMH4 CT97-2412), the Curie Institute, the Centre National de la Recherche Scientifique, the Institut National de la Santé et de la Recherche Médicale, the Deutsche Forschungsgemeinschaft, and the Association Franco-Israélienne pour la Recherche Scientifique et Technologique. K.P.L. is supported by the Hermann and Lilly Schilling Foundation. We thank Constantino Sotelo for support and advice, Michael Armstrong-James, Antonio Persico, and Cecile Lebrand for unpublished data, Nicole Ropert, Serge Marty, and Olivier Cases for discussions, and Diana Haranger for animal care.

Correspondence should be addressed to Isabelle Seif, Centre National de la Recherche Scientifique, Unité Mixte de Recherche 146, Institut Curie, 91405 Orsay, France. E-mail: Isabelle.Seif@curie.u-psud.fr.

Copyright $(\subset 2001$ Society for Neuroscience $0270-6474 / 01 / 210884-\bullet \$ 15.00 / 0$
}

ing pattern (Cases et al., 1996; Vitalis et al., 1998; Upton et al., 1999). Close scrutiny of the molecular mechanisms underlying the effects of 5-HT may provide a better understanding of the similarities and differences of map formation in the two sensory systems. In addition, it could point to additional sites for brain abnormalities caused by an excess of 5-HT during development and shed light on the mechanisms by which monoamine oxidase deficiency causes behavioral deficits in mice and in humans (Collins et al., 1992; Brunner et al., 1993; Cases et al., 1995).

We examined the role of two candidate molecules that could mediate the effects of excess 5-HT: the 5-HT transporter (5HTT) and the 5-HT1B receptor. Both molecules are expressed in retinal ganglion cells (RGCs) and primary sensory thalamic nuclei during the period when the segregation of retinogeniculate and thalamocortical projections occurs (Bennett-Clarke et al., 1993, 1996; Lebrand et al., 1996; Hansson et al., 1998; Upton et al., 1999). 5-HT is internalized via 5-HTT in RGCs and thalamic neurons and is easily detected in axon terminals (Lebrand et al., 1996; Cases et al., 1998; Upton et al., 1999). The presence of the vesicular monoamine transporter VMAT2 within the same neurons could allow internalized 5-HT to be stored in vesicles and used as a cotransmitter of glutamate. In MAOA KO mice, 5-HT cannot be degraded normally and accumulates all along the retinal and thalamic neurons (Cases et al., 1998; Upton et al., 1999). Increased internalization and accumulation of 5-HT in these neurons could be an important factor mediating the dele- 
terious effects of excess 5-HT in MAOA KO mice. However, overstimulation of some 5-HT receptors is likely to be the primary factor. The 5-HT1B receptor is known to inhibit the release of glutamate in the retinotectal pathway (Mooney et al., 1994) and the thalamocortical somatosensory pathway (Rhoades et al., 1994). Therefore, in both sensory systems, excessive activation of 5-HT1B receptors could prevent activity-dependent processes involved in the patterning of afferents.

To examine the role of these two molecules, we have taken a genetic approach. A partial disruption of the patterning of retinogeniculate and somatosensory thalamocortical projections was observed in 5-HTT KO mice. Using MAOA/5-HTT double KO (DKO) mice, we show that 5-HT accumulation in the extracellular space suffices to cause total disruption of the patterning of these projections. On the other hand, the removal of 5-HT1B receptors in MAOA KO, 5-HTT KO, and MAOA/5-HTT DKO mice allows a normal segregation of the retinogeniculate and the somatosensory projections. Thus, our results point to a similarity between the mechanisms of map formation in the visual and somatosensory systems: in both systems, the 5-HT1B receptor has an essential role in mediating the deleterious effects of excess 5-HT.

\section{MATERIALS AND METHODS}

Animals. Normal mice (C3H/HeJ, 129/SvPas, and C57BL/6ByJ) and knock-out mice were produced at the Curie Institute (Orsay, France). The day of birth was counted as postnatal day $0(\mathrm{P} 0)$. To generate the DKO and triple knock-out (TKO) mice, we crossed mice from three previously characterized knock-out strains lacking either MAOA, 5-HTT, or 5-HT1B: (1) The original MAOA KO strain has a $\mathrm{C} 3 \mathrm{H} / \mathrm{HeJ}$ genetic background (Tg8 strain; Cases et al., 1995, 1996); we backcrossed these mice onto the $129 / \mathrm{SvPas}$ and C57BL/6ByJ backgrounds for up to 10 generations. (2) The original 5-HTT KO strain has a mixed genetic background (129/Sv, C57BL/6J, and CD-1) (Bengel et al., 1998); we backcrossed these mice onto the $\mathrm{C} 3 \mathrm{H} / \mathrm{HeJ}$ background for up to four generations. (3) The original 5-HT1B KO strain has a mixed 129/Sv genetic background (cf. Saudou et al., 1994; Hen, 1999, JB construct); we backcrossed these mice onto the $\mathrm{C} 3 \mathrm{H} / \mathrm{HeJ}$ background for up to 10 generations. The $\mathrm{C} 3 \mathrm{H}$-backcrossed 5-HT1B KO mice have smaller litters (one to four pups) than normal $\mathrm{C} 3 \mathrm{H}$ mice (five to eight pups) and the original 5-HT1B KO strain (five to nine pups).

To obtain MAOA/5-HT1B DKO mice, we crossed MAOA KO $(\mathrm{C} 3 \mathrm{H})$ females with 5-HT1B KO (129) males. First generation (F1) males are knock-out for the X-linked MAOA mutation and heterozygous for the chromosome-9-linked 5-HT1B mutation [control F1 MAOA KO males were obtained by crossing the MAOA $\mathrm{KO}(\mathrm{C} 3 \mathrm{H})$ females with normal $129 / \mathrm{SvPas}$ males]. F2 progeny were genotyped by PCR analysis. Genotype frequencies were as expected: $26 \mathrm{MAOA} / 5-\mathrm{HT} 1 \mathrm{~B}$ DKO mice were obtained from a total of $210 \mathrm{~F} 2$ mice. Two outbred strains (MAOA KO and MAOA/5-HT1B DKO) were derived from these F2 mice, both with a $\mathrm{C} 3 \mathrm{H} / 129$ heterogeneous background. The fertility of the DKO mice is highly variable and is probably modulated by the mixed genetic background. Histochemical studies on the DKO mice (F2 and subsequent generations) revealed also some heterogeneity. To reduce this heterogeneity, we obtained new MAOA/5-HT1B DKO F2 mice by crossing MAOA KO $(\mathrm{C} 3 \mathrm{H})$ females with $\mathrm{C} 3 \mathrm{H}$-backcrossed 5-HT1B KO males (in the F1 generation, males are knock-out for MAOA and heterozygous for the 5-HT1B mutation).

To obtain MAOA/5-HTT DKO mice, we crossed MAOA KO $(\mathrm{C} 3 \mathrm{H})$ females with heterozygous 5-HTT KO (129-C57BL-CD1) males. Controls of the MAOA/5-HTT DKO F2 mice were the 5-HTT KO F2 littermates. Additional controls were 5-HTT KO mice obtained by crossing normal $\mathrm{C} 3 \mathrm{H}$ mice with the same heterozygous 5-HTT KO (129C57BL-CD1) males. Histochemical studies were done on F2 mice and subsequent generations.

To obtain 5-HTT/5-HT1B DKO mice, we crossed 5-HT1B KO (129) females with 5-HTT KO (C3H-129-C57BL-CD1) males. We obtained C3H-enriched 5-HTT/5-HT1B DKO mice by crossing C3H-backcrossed heterozygous 5-HT1B KO mice with $\mathrm{C} 3 \mathrm{H}$-backcrossed heterozygous 5-HTT KO mice. To obtain MAOA/5-HTT/5-HT1B TKO mice, we crossed MAOA/5-HTT DKO F4 (C3H-129-C57BL-CD1) females with 5-HTT/5-HT1B DKO (C3H-129-C57BL-CD1) F3 males.
Immunocytochemistry of 5-HT and 5-HTT. P3, P4, P5, P6, P7 and P8 mice were anesthetized with chloral hydrate and perfused through the aorta with $4 \%$ paraformaldehyde in $0.1 \mathrm{~m}$ sodium phosphate buffer. Brains were collected. In most cases, the cerebral hemispheres were separated, and the cortex was flattened between two glass slides and post-fixed for several days $(2-15 \mathrm{~d})$. After cryoprotection in phosphate buffer with $30 \%$ sucrose for $2-10$ d, coronal sections of the brains or tangential sections of the flattened hemispheres were frozen and cut to $40-\mu$ m-thick sections with a microtome. 5-HT distribution was studied with a rat monoclonal anti-5-HT antibody (1:50 dilution) from SeraLab. 5-HTT distribution was studied with a rabbit polyclonal antibody (1:5000 dilution) from Calbiochem (La Jolla, CA). The sections were rinsed in PBS + (PBS with $0.2 \%$ gelatin and $0.25 \%$ Triton X-100) for at least 30 min, and incubated overnight at room temperature with the primary antibody in PBS + with $0.02 \%$ sodium azide. After washing in PBS $+(4 \times$ $15 \mathrm{~min}$ ), sections were incubated with the biotinylated secondary antibody [1:200 dilution; rabbit anti-rat Ig from Dako (Carpinteria, CA) and goat anti-rabbit Ig from Vector Laboratories (Burlingame, CA)] in PBS+ for $2 \mathrm{hr}$, rinsed, and incubated for $1.5 \mathrm{hr}$ with the streptavidin-peroxidase complex (1:400 dilution; Amersham) in PBS + (all at room temperature). After washing in $0.05 \mathrm{M}$ Tris buffer, $\mathrm{pH} 7.8$, with $0.2 \%$ gelatin, peroxidase was revealed in $0.02 \% 3,3^{\prime}$-diaminobenzidine tetrahydrochloride (Sigma, St. Louis, MO), $0.003 \% \mathrm{H}_{2} \mathrm{O}_{2}$, and $0.6 \%$ nickel ammonium sulfate. Sections were mounted on SuperFrost/Plus glass slides, dehydrated, and covered in Entellan. Images of barrels (see Fig. $6 G, H$ ) are photomontages from the most relevant sections.

Cytochrome oxidase (CO) cytochemistry. $\mathrm{P} 3, \mathrm{P} 5, \mathrm{P} 7, \mathrm{P} 8, \mathrm{P} 9, \mathrm{P} 10, \mathrm{P} 12$ and adult mice were perfused with $4 \%$ paraformaldehyde. Brains were dissected, and the cortices were flattened between two glass slides, post-fixed for $24 \mathrm{hr}$, and cryoprotected in $0.1 \mathrm{M}$ phosphate buffer with $30 \%$ sucrose. The hemispheres were cut tangentially to $40-\mu \mathrm{m}$-thick sections. All the sections were used for CO cytochemistry. Alternatively, dissected brains were post-fixed for $24 \mathrm{hr}$, cryoprotected, and serially cut in $40-\mu \mathrm{m}$-thick coronal sections. Sections were processed as described by Wong-Riley and Welt (1980). Cytochrome C was occasionally omitted from the reaction mixture. Sections were mounted on SuperFrost/Plus glass slides, dehydrated, and covered in Entellan. However, because the $\mathrm{CO}$ staining of the barreloids in the thalamus was best observed when sections were immersed in water, photographs were taken before the sections were dehydrated. Images of barrels (see Figs. 5, 6) are photomontages from the most relevant sections, whereas images of barreloids (see Figs. 5, 6) correspond to single optimum sections.

Nissl staining. P7, P16, and adult mice were perfused with $4 \%$ paraformaldehyde, and brains were cryoprotected and sectioned as for immunocytochemistry. Serial $40-\mu \mathrm{m}$-thick sections, cut tangentially on the flattened hemispheres, were mounted on SuperFrost/Plus glass slides. The entire series of sections were used for Nissl staining as previously described by Rice and Van der Loos (1977). Slides were immersed in a solution made of $180 \mathrm{ml}$ of $1.36 \%$ sodium acetate and $70 \mathrm{ml}$ of $0.6 \%$ acid acetic for $10 \mathrm{~min}$, then placed in the same buffer with $0.4 \%$ thionin for 5-10 min. Sections were rinsed in water, dehydrated, and covered in Entellan. Images of cortical barrels in Figure 8 represent single sections.

Anterograde axonal tracing by intraocular horseradish peroxidase (HRP) injections. P30 and older mice were anesthetized with $4 \%$ chloral hydrate ( $0.1 \mathrm{ml}$, i.p. per $10 \mathrm{mg}$ of body weight). A $60 \%$ horseradish peroxidase (type VI; Sigma) solution was prepared in physiological saline, just before the experiment. Intraocular injections were made into the vitreous chamber of the left eye with a Hamilton syringe inserted just behind the corneoscleral margin of the eye. Four microliters of the solution were injected, and the animals were returned to their home cages for $24 \mathrm{hr}$. Mice were then anesthetized and perfused through the aorta with $40 \mathrm{ml}$ of ice-cold fixative mixture (1\% paraformaldehyde and $0.25 \%$ glutaraldehyde in $0.1 \mathrm{M}$ phosphate buffer, $\mathrm{pH}$ 7.4). The brains were dissected out and cryoprotected in $0.1 \mathrm{~m}$ phosphate buffer with $10 \%$ sucrose overnight. Brains were frozen and serially sectioned in the coronal plane. The serial $40-\mu \mathrm{m}$-thick sections were collected in ice-cold $0.1 \mathrm{M}$ phosphate buffer and stored at $4{ }^{\circ} \mathrm{C}$. The next day, while maintained at $4^{\circ} \mathrm{C}$ and protected from light, the sections were reacted in three steps: (1) a 10 min rinse in $0.1 \mathrm{M}$ phosphate buffer, $\mathrm{pH} 3.3$; (2) immersion in a tetramethylbenzidine $(\mathrm{TMB})$ solution $(0.067 \% \mathrm{w} / \mathrm{v})$ with nitroprussiate $(0.0017 \% \mathrm{w} / \mathrm{v})$ to protect TMB against oxidation as previously described (Mesulam et al., 1980 ); and (3) addition of $0.006 \% \mathrm{H}_{2} \mathrm{O}_{2}$ to start the reaction; $\mathrm{H}_{2} \mathrm{O}_{2}$ was added repeatedly at $20 \mathrm{~min}$ intervals until the blue product of the HRP-TMB reaction was deemed complete (generally three times). Sections were then rinsed in $0.1 \mathrm{M}$ phosphate buffer, $\mathrm{pH} 3.3$, and immediately 
mounted on glass slides. The next day, the slides were immersed in methyl salicylate (Adams, 1980) for $3 \mathrm{~min}$, dehydrated in graded alcohols (1 min per bath), cleared in xylene, and coverslipped in the usual way. Slides were kept at $4^{\circ} \mathrm{C}$ in light-proof boxes.

HPLC procedure. $\mathrm{P} 2$ and $\mathrm{P} 6$ mice were rapidly decapitated, and the brains were removed and immersed in liquid nitrogen (the whole procedure lasting $<1 \mathrm{~min}$ ). Samples were weighed and kept at $-80^{\circ} \mathrm{C}$ (up to 2 months) before the HPLC procedure: (1) samples were sonicated for 5 sec in 10 volumes $(\mathrm{v} / \mathrm{w})$ of $0.1 \mathrm{~N}$ perchloric acid, $0.05 \%$ disodium EDTA, and $0.05 \%$ sodium metabisulfite; (2) after centrifugation for $20 \mathrm{~min}$ at $30,000 \times g, 200 \mu \mathrm{l}$ of the supernatant was collected; (3) supernatant aliquots were neutralized on ice by adding $20 \mu \mathrm{l}$ of $2 \mathrm{M}$ potassium phosphate buffer, $\mathrm{pH} 7.4$, (10 min); endogenous ascorbic acid was degraded by adding $10 \mu \mathrm{l}$ of $0.02 \%$ ascorbate oxidase ( $5 \mathrm{~min}$ ); and (4) after centrifugation for $20 \mathrm{~min}$ at $30,000 \times g, 10 \mu \mathrm{l}$ of the supernatant was collected and injected onto a Beckman Ultrasphere $5 \mu \mathrm{m}$ IP column. The

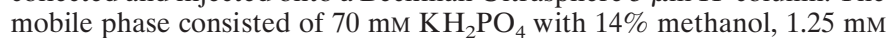
octane sulfonate, $0.1 \mathrm{~mm}$ disodium EDTA, and $2.1 \mathrm{~mm}$ triethylamine, with the $\mathrm{pH}$ adjusted to 3.02 with solid citric acid. 5-HT and 5-HIAA eluted from the column were quantified by electrochemical detection (at $0.65 \mathrm{~V}$ ), and concentrations were calculated in picograms per milligram of brain (Hamon et al., 1988).

Drug treatments. To reduce 5-HT levels in MAOA/5-HTT DKO or MAOA/5-HT1B DKO pups, daily subcutaneous injections of parachlorophenylalanine (PCPA) $(300 \mathrm{mg} / \mathrm{kg})$, an inhibitor of tryptophan hydroxylase, were administered in the neck from P0 to P8. PCPA methyl ester hydrochloride (Sigma) was dissolved in water $(20 \mathrm{mg} / \mathrm{ml})$. Control littermates received daily injections of equal volumes of water. Pups were killed at P16. Similar treatments were administered to MAOA KO mice from P0 to P14 (PCPA, $n=23$; vehicle, $n=15$ ). After weaning, females were housed in groups, and males were mated with normal females. Mice were used for behavioral testing within 6 months.

Beam-walking task. Naive mice of both sexes, 2 months or older, were placed individually on a narrow wooden beam (see Fig. 7) and returned to their home cage for a $10 \mathrm{~min}$ period after they reached the end of the beam. Training sessions were repeated until the mice ceased grasping the edges of the beam. Typically, normal $\mathrm{C} 3 \mathrm{H} / \mathrm{He}$ mice require less than five sessions to walk normally, whereas MAOA KO mice $(\mathrm{C} 3 \mathrm{H} / \mathrm{He}$ background) never cease crawling, independent of speed, even after several days of training (six sessions per day) (Cases et al., 1995). Only postures were recorded. Walking latency and speed were not measured in the present study because they may reflect differences in motivation between genotypes. Walking abnormalities in MAOA KO mice were easily observed on the $\mathrm{C} 3 \mathrm{H} / \mathrm{He}$ and $129 / \mathrm{Sv}$ backgrounds but were less striking on the C57BL/6 and BALB/c backgrounds, apparently because of different hindpaw placing in the latter strains, which facilitates this task.

\section{RESULTS}

\section{Visual system: retinogeniculate projections in MAOA knock-out mice}

In the dorsal lateral geniculate nucleus (dLGN), retinal afferents from the ipsilateral and contralateral eyes segregate into eyespecific domains (Dräger and Olsen, 1980; Godement et al., 1984). This pattern emerges progressively during postnatal development. Initially retinogeniculate terminals from each eye extend beyond their normal territory, and between $\mathrm{P} 4$ and $\mathrm{P} 8$, axons that innervate inappropriate territories retract, and the adult pattern of projections is established: ipsilateral fibers are confined to a mediodorsal area of the dLGN, whereas contralateral fibers are distributed in all the dLGN except for a mediodorsal gap corresponding to the ipsilateral territory (Fig. $1 A, B$ ). These projections vary among mouse strains (LaVail et al., 1978). Relevant to the present study is our observation that the ipsilateral and contralateral segregation is very sharp in the wild-type $\mathrm{C} 3 \mathrm{H} / \mathrm{He}$ strain (Fig. $1 A, B$; Upton et al., 1999), whereas in the wild-type $129 / \mathrm{Sv}$ strain, the contralateral gap and ipsilateral patch are not sharply delineated (data not shown). This is of importance because the 129/Sv strain is commonly used in the generation of knock-out mice (such as the original 5-HT1B KO and 5-HTT KO strains).

In MAOA KO mice with a $\mathrm{C} 3 \mathrm{H} / \mathrm{He}$ or $\mathrm{C} 57 \mathrm{BL} / 6$ genetic back-
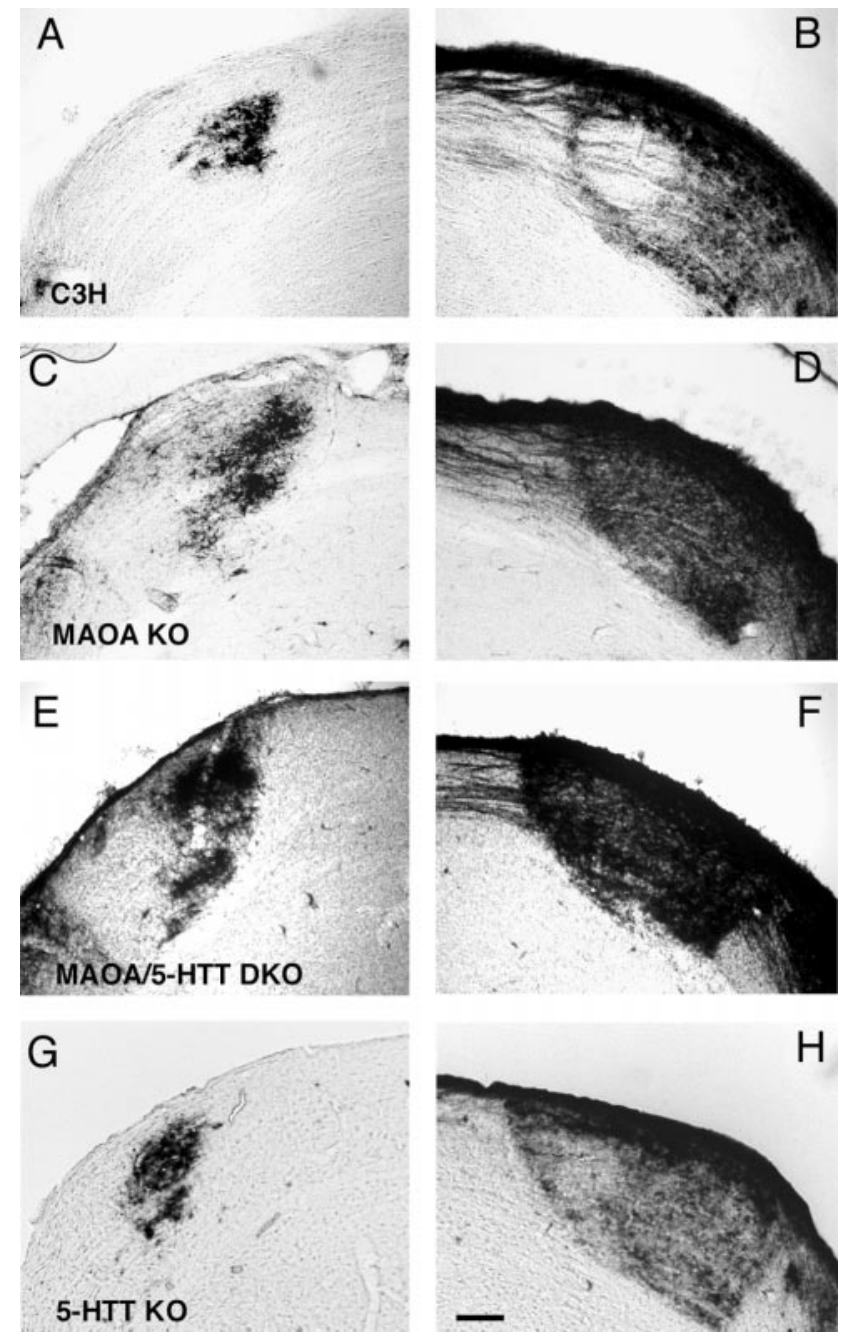

Figure 1. Lack of segregation of retinal afferents in MAOA KO mice, 5-HTT KO mice, and MAOA/5-HTT DKO mice. HRP was injected into the left eye in adult mice ( $\mathrm{P} 30$ or more). Ipsilateral projections to the dLGN are shown in the left-hand column $(A, C, E, G)$, and contralateral projections are shown in the right-hand column $(B, D, F, H)$. The sections illustrated were chosen at similar rostrocaudal levels. $A$, $B$, In wild-type $\mathrm{C} 3 \mathrm{H}$ mice, the eye-specific segregation is clear with tightly packed ipsilateral retinal axons $(A)$ and a clear gap contralaterally $(B)$. Within this gap, the only contralateral fibers correspond to retinal axon bundles traversing the nucleus. $C$, $D$, In MAOA KO mice (mixed C3H-129 genetic background), the ipsilateral projections are diffuse in the dLGN $(C)$, and no gap is visible contralaterally $(D)$. This aspect is identical to that of the MAOA KO mice having an inbred strain background $(\mathrm{C} 3 \mathrm{H}, 129$, or C57BL). $E$, $F$, In MAOA/5-HTT DKO mice (mixed 129-C3H-C57BL$\mathrm{CD} 1$ background), there is no segregation of the ipsilateral and contralateral retinal projections. $G, H$, In 5-HTT KO mice (C3H-backcrossed), the contralateral projection does not retract completely from the normal ipsilateral territory. Scale bar, $0.1 \mathrm{~mm}$.

ground, retinal inputs do not segregate in the dLGN (Upton et al., 1999). The same phenotype was observed here in MAOA KO mice with a $\mathrm{C} 3 \mathrm{H} / 129 \mathrm{~F} 1$ hybrid background (Fig. $3 C, D$ ), in MAOA $\mathrm{KO}$ mice with a $\mathrm{C} 3 \mathrm{H} / 129$ heterogeneous background (Fig. $1 C, D$ ), and in 129-backcrossed MAOA KO mice (data not shown). This developmental abnormality is permanent, but can be prevented by reducing 5-HT brain levels with PCPA, an inhibitor of tryptophan hydroxylase, from P0 to P15 (Upton et al., 1999).

Here we examined two mechanisms whereby 5-HT could exert its effects: via the serotonin transporter (5-HTT) and via the 5-HT1B receptor. 
A
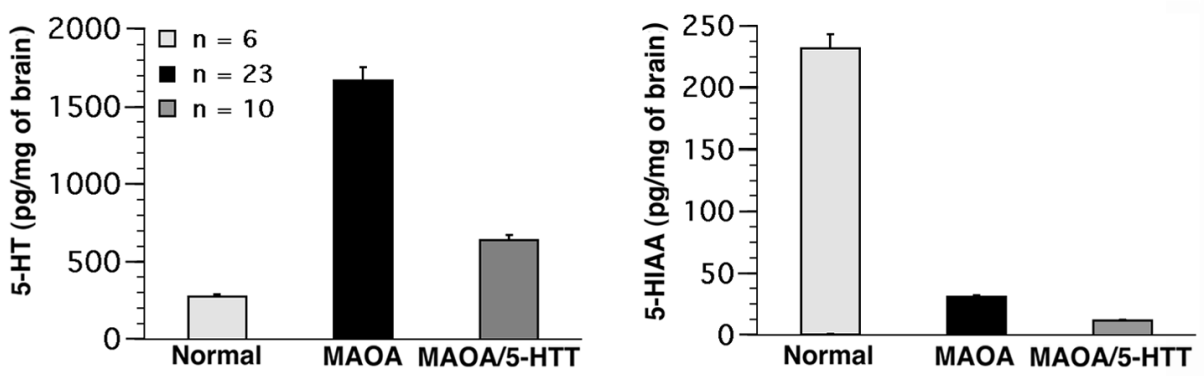

MAOA KO

$\mathrm{B}$

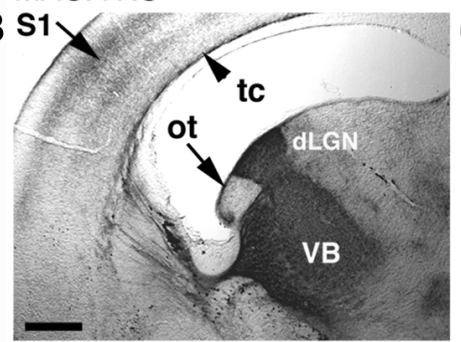

MAOA/5-HTT DKO

E S1

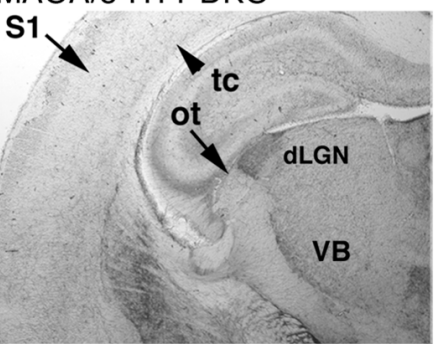

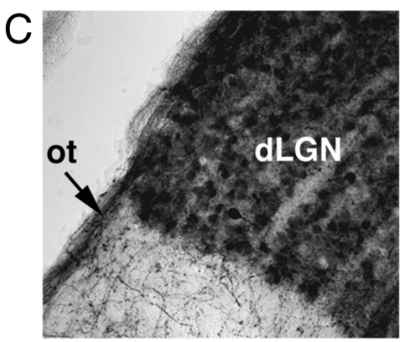

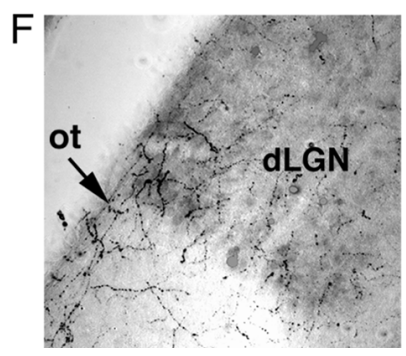

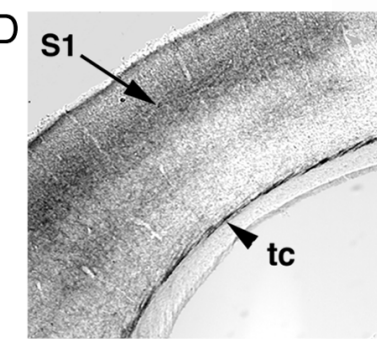

G $\mathbf{s}$

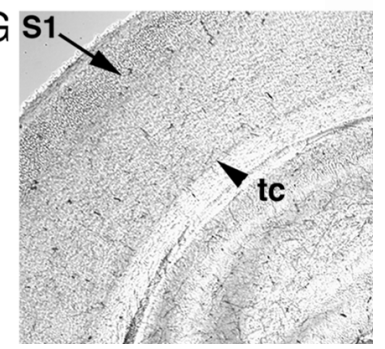

Figure 2. Comparison of 5-HT brain levels and 5-HT localization in the MAOA KO and MAOA/5-HTT DKO mice. $A$, 5-HT and 5-HIAA brain levels were measured in normal and mutant mice aged P2. In normal mice, the ratio 5-HT/5-HIAA is low: $1.2(5-\mathrm{HT}$ concentration, $278 \pm 14$ $\mathrm{pg} / \mathrm{mg}$; 5-HIAA concentration, $232 \pm 15$ $\mathrm{pg} / \mathrm{mg}$; mean $\pm \mathrm{SEM}, n=6$ ). In MAOA $\mathrm{KO}$ mice, the ratio 5-HT/5-HIAA is very high: 53.9 (5-HT, $1672 \pm 52 \mathrm{pg} / \mathrm{mg}$; 5-HIAA, $31 \pm 2 \mathrm{pg} / \mathrm{mg} ; n=23)$. In MAOA/5-HTT DKO mice, the ratio 5-HT/5-HIAA is similarly high: 53.5 (5HT, $642 \pm 24 \mathrm{pg} / \mathrm{mg}$; 5-HIAA, $12 \pm 2$ $\mathrm{pg} / \mathrm{mg} ; n=10) . B-D, 5$-HT immunostaining in the MAOA KO mice (aged P4) shows an excessive accumulation of the amine in the VB and dLGN neurons $(B)$, as well as in the somatosensory thalamocortical fibers $(t c)$ in the somatosensory cortex $(\mathrm{S} 1)(B, D)$. 5-HT is also visible in the retinal axons that course superficially to the dLGN in the optic tract $(o t)(C)$. $E-G$, In MAOA/5-HTT DKO mice (P4), 5-HT immunostaining is strongly reduced in the dLGN $(E, F)$, the VB $(E)$, and S1 $(E, G)$. Retinal axons in the optic tract contain no detectable 5-HT $(F)$. Scale bar: $B, E, 0.4 \mathrm{~mm} ; C, F, 0.025 \mathrm{~mm} ; D, G$, $0.2 \mathrm{~mm}$.

\section{Visual system: effects of removing the 5-HTT gene in MAOA KO mice}

Both in normal and MAOA KO mice, 5-HTT is expressed by a fraction of RGCs during the period of eye-specific segregation of retinal inputs, with prominent expression in the RGCs that project ipsilaterally to the dLGN (Upton et al., 1999). 5-HTT is also transiently expressed by the dLGN neurons (Lebrand et al., 1998). In normal mice, 5-HT is detected in the axon terminals of dLGN neurons and of ipsilaterally projecting RGCs, whereas in MAOA KO mice, 5-HT accumulates all along the dLGN neurons and RGCs (Fig. 2B,C) (Cases et al., 1998; Upton et al., 1999). To evaluate whether massive uptake and accumulation of 5-HT in RGCs and dLGN neurons play a role in the lack of eye-specific patterning in the dLGN of MAOA KO mice, we crossed them with 5-HTT KO mice (Bengel et al., 1998). We obtained MAOA/ 5-HTT double knock-out (DKO) mice with a heterogeneous background (see Materials and Methods).

As analyzed with 5-HT immunocytochemistry in P5 MAOA/ 5-HTT DKO mice, no 5-HT accumulation was observed in retinal axons in the optic tract and terminals (Fig. 2E,F), and only a low residual accumulation was noted in the soma of target dLGN neurons but not in their cortical terminals, confirming that 5-HT accumulation in RGCs and dLGN neurons is mainly via 5-HTT (Lebrand et al., 1996; Cases et al., 1998). In newborn MAOA/5HTT DKO mice (P2), brain levels of 5-HT were increased 2.3fold compared with normal mice, but were reduced 2.6-fold relative to MAOA KO mice (Fig. $2 A$ ). The ratio between 5-HT and its metabolite 5-hydroxyindoacetic acid (5-HIAA) did not differ between MAOA KO mice and MAOA/5-HTT DKO mice (53.9 vs 53.5), suggesting decreased 5-HT synthesis in the latter mice. However, extracellular levels of 5-HT in MAOA/5-HTT DKO mice are likely to be more elevated than in MAOA KO mice, at least in certain regions. Indirect evidence for this is provided by the increased accumulation of 5-HT in neurons of the central amygdala, suprachiasmatic and subincertal nuclei, and in catecholaminergic neurons (including nigrostriatal terminals), as compared with the MAOA KO mice (data not shown; for discussion of 5-HT uptake and accumulation in catecholaminergic neurons and diverse nonmonoaminergic cell groups in MAOA KO mice, see Cases et al., 1998).

In MAOA/5-HTT DKO mice aged P14 and P40 $(n=4)$, HRP labeling of retinal projections showed that the ipsilateral and contralateral retinogeniculate fibers did not segregate in the dLGN (Fig. 1E,F) similarly to the MAOA KO (Fig. $1 C, D$ ). Because the lack of segregation in the MAOA/5-HTT DKO mice was possibly attributable to the total lack of 5-HT in the RGCs (making it impossible to use 5-HT as a borrowed neurotransmitter for instance), we administered the inhibitor of 5-HT synthesis PCPA (300 $\left.\mathrm{mg} \cdot \mathrm{kg}^{-1} \cdot \mathrm{d}^{-1}\right)$ to MAOA/5-HTT DKO mice during the first postnatal week ( $\mathrm{P} 0-\mathrm{P} 8)$. The segregation pattern of retinal afferents was comparable with that of wild-type $129 / \mathrm{Sv}$ mice (data not shown), implying that internalized 5-HT is not required for eye-specific segregation and stressing the importance of excess extracellular 5-HT in preventing this segregation.

During the course of this study, we generated control 5-HTT $\mathrm{KO}$ mice with a heterogeneous background similar to that of the MAOA/5-HTT DKO mice, as well as 5-HTT KO mice with a $\mathrm{C} 3 \mathrm{H}-\mathrm{enriched}$ background (see Materials and Methods). These mice showed an incomplete segregation of retinogeniculate fibers $(n=10)$ : the contralateral projection did not retract completely 
from the normal ipsilateral territory (Fig. $1 G, H$ ). This finding indicates a requirement for 5-HT clearance via 5-HTT during the development of the retinogeniculate system.

Altogether, these results suggest that excess extracellular 5-HT is a necessary and sufficient factor in preventing eye-specific segregation in the dLGN and point to a role of 5-HT receptors expressed on the cell surface.

\section{Visual system: effects of removing the 5-HT1B gene in MAOA KO mice and MAOA/5-HTT DKO mice}

Among the 5-HT receptors that could be overly stimulated in the MAOA KO mice and affect the capacity of RGCs or dLGN neurons to receive and generate signals important for eye-specific segregation, the 5-HT1B receptor is a likely candidate because it is expressed by RGCs and dLGN neurons during development (Bennett-Clarke et al., 1993; Upton et al., 1999) and stimulation of this receptor mediates presynaptic inhibition of adult retinal inputs to the superior colliculus and suprachiasmatic nucleus (Mooney et al., 1994; Pickard et al., 1999). This receptor is likely to modulate the transmission of patterned spontaneous neural activity arising from the retina to the dLGN. We analyzed the effects of removing one or both alleles of the 5-HT1B gene in wild-type, MAOA KO, and MAOA/5-HTT DKO mice.

In 5-HT1B KO mice with the original 129 background (P14 and $\mathrm{P} 30 ; n=5)$ or with a C3H-enriched background (P30; $n=6)$, HRP injections into one eye showed a wild-type pattern of segregation of the ipsilateral and contralateral retinal fibers in the dLGN (Fig. $3 A, B)$. Thus, 5-HT1B receptors do not seem essential for the establishment of eye-specific domains in the dLGN of normal mice.

In MAOA KO mice lacking a single allele of the 5-HT1B gene and having a $\mathrm{C} 3 \mathrm{H} / 129 \mathrm{~F} 1$ hybrid background $(n=3)$, a partial segregation of retinal inputs was observed at P30. The size of the ipsilateral projection was unchanged (Fig. 3E), compared with control F1 MAOA KO mice (Fig. 3C), whereas the contralateral retinal projection showed a thinning out in the central region of the dLGN, allowing a gap to be delineated (Fig. $3 F$ ), although it did not appear as devoid of fibers as in normal F1 C3H/129 mice (data not shown).

In MAOA/5-HT1B DKO mice aged P30 ( $n=10$ with a $\mathrm{C} 3 \mathrm{H} / 129$ background and $n=3$ with a $\mathrm{C} 3 \mathrm{H}$ background), HRP injections into one eye showed a wild-type segregation of the ipsilateral and contralateral retinal fibers: in the dLGN of $\mathrm{C} 3 \mathrm{H}-$ enriched DKO mice, ipsilateral terminals were well compacted (Fig. 3G), and there was a clear mediodorsal gap (Fig. 3H), with a similar rostrocaudal extension as in normal $\mathrm{C} 3 \mathrm{H}$ mice $(\sim 450$ $\mu \mathrm{m})$. To determine whether this corrective effect was attributable to a reduction in 5-HT levels, we measured 5-HT (and 5-HIAA) brain levels in the MAOA/5-HT1B DKO mice at P2 and P6. We found that the lack of 5-HT1B receptors does not affect 5-HT and 5-HIAA levels in the brain: these are similarly abnormal in the double knock-outs and in the MAOA KO mice (Fig. 4A). 5-HTimmunostaining showed that 5-HT accumulates in the retinal axons and target dLGN neurons of the MAOA/5-HT1B DKO mice (Fig. $4 D, E$ ) as in MAOA KO mice (Fig. $4 B, C$ ). In wild-type mice, a patch of 5-HT immunoreactivity corresponding to 5-HT uptake by ipsilateral retinogeniculate terminal axons is transiently visible in the dLGN (c.f. Upton et al., 1999, their Fig. 4G). In P6 MAOA/5-HT1B DKO mice, we found 5-HT immunolabeling in a patch of terminals concentrated in the mediodorsal dLGN (Fig. $4 E$ ) similar in its topography to that observed in normal mice at P6. In MAOA KO mice, this patch is not visible because of the diffuse nature of the ipsilateral projection (Fig. 4C). Therefore,
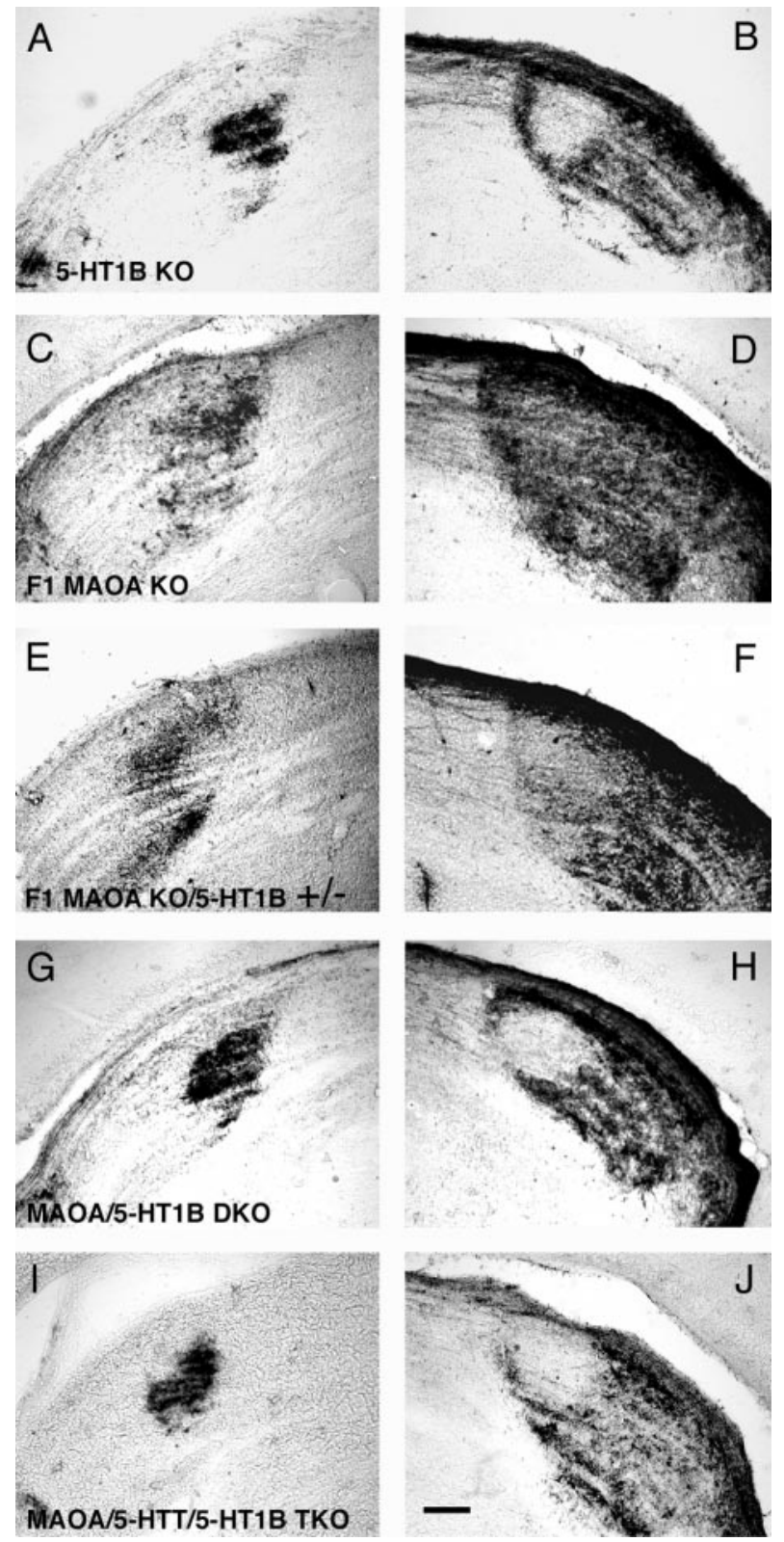

Figure 3. Deficient segregation of retinogeniculate axons is mediated by 5-HT1B receptors. HRP was injected into the left eye in adult mice (P30 or more). Ipsilateral projections to the dLGN are shown on the left $(A, C, E$, $G, I)$, and contralateral projections on the right $(B, D, F, H, J)$. The sections illustrated were chosen at similar rostrocaudal levels. $A, B$, Normal segregation in 5-HT1B KO mice (C3H-backcrossed). $C, D, \mathrm{~F} 1$ control MAOA $\mathrm{KO}$ mice $[\mathrm{F} 1$ hybrid males from crosses between MAOA KO $(\mathrm{C} 3 \mathrm{H})$ females and normal 129 males] have identical abnormalities as the other MAOA KO strains (Fig. $1 C, D$ ). $E, F, F 1$ MAOA KO mice that are heterozygous knock-outs for the 5-HT1B gene [F1 hybrid males from crosses between MAOA KO (C3H) females and 5-HT1B KO (129) males] display a partial correction of the abnormalities with the outline of a gap contralaterally $(F)$, whereas the ipsilateral projections are still exuberant (E). $G, H$, In MAOA/5-HT1B DKO mice (C3H-backcrossed), the eyespecific segregation is normal and comparable with that of wild-type control mice (Fig. 1A,B). I, $J$, In MAOA/5-HTT/5-HT1B TKO mice, the eye-specific segregation of retinogeniculate projections is also normal. Scale bar, $0.1 \mathrm{~mm}$.

despite continued increases of 5-HT levels in the extracellular and intracellular space, the lack of 5-HT1B receptor completely restores the capacity of retinal fibers to segregate in the dLGN. 
A

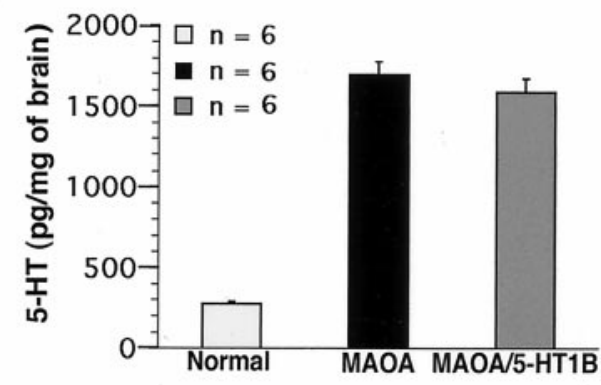

MAOA KO

B S1

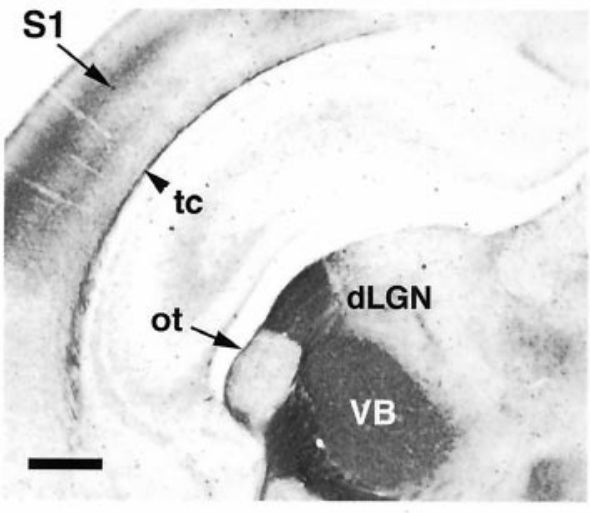

MAOA/5-HT1B DKO

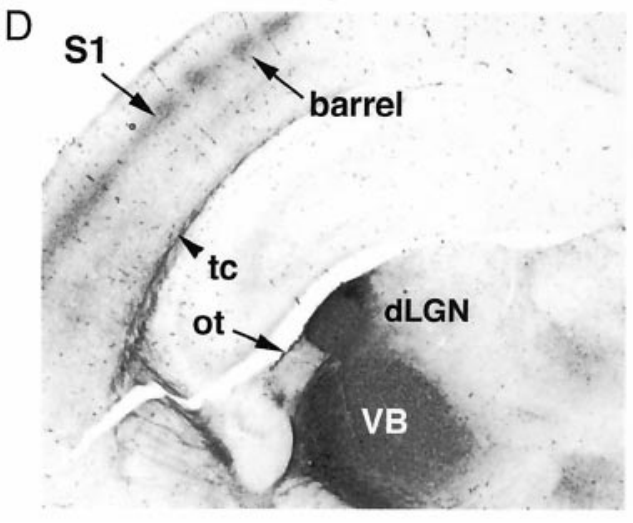

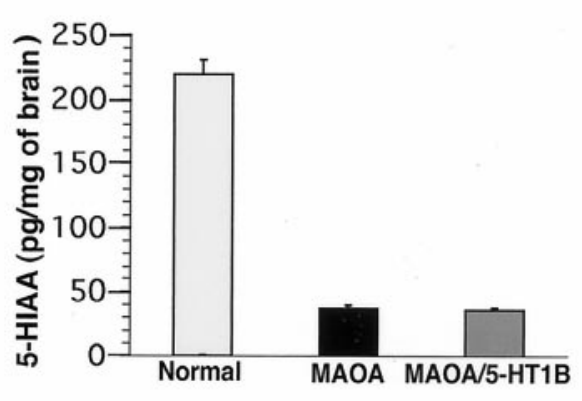

C

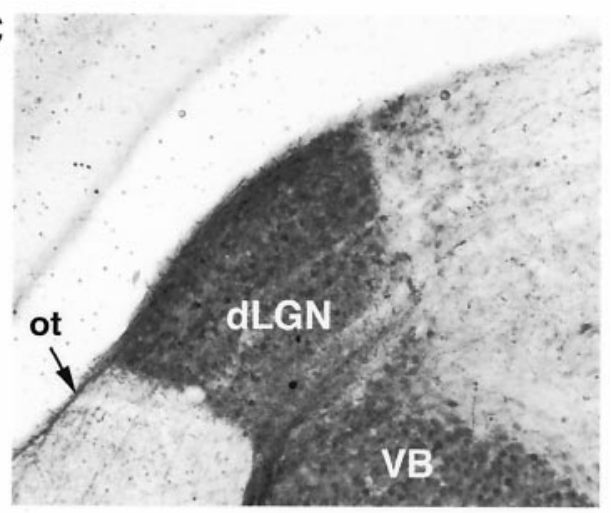

E

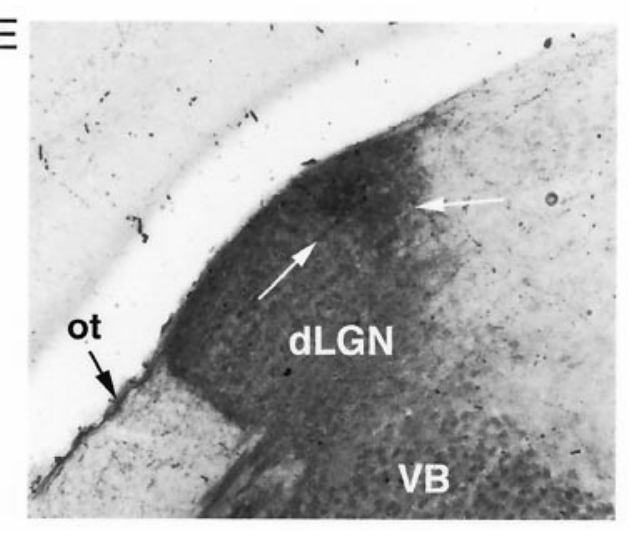

Figure 4. Comparison of 5-HT brain levels and 5-HT localization in MAOA KO and MAOA/5-HT1B DKO mice. $A$, In P6 MAOA KO (5-HT concentration, $1694 \pm$ $38 \mathrm{pg} / \mathrm{mg}$; mean $\pm \mathrm{SEM}, n=6)$ and MAOA/5-HT1B DKO mice (5-HT, $1592 \pm 34 \mathrm{pg} / \mathrm{mg} ; n=6), 5$-HT brain levels are similarly increased compared with the normals $(5-\mathrm{HT}, 278 \pm 9 \mathrm{pg} / \mathrm{mg}$; $n=6)$. In both mutants, the 5-HIAA brain levels are very low (5-HIAA in MAOA KO, $38 \pm 2 \mathrm{pg} / \mathrm{mg}$; 5-HIAA in MAOA/5-HT1B DKO, $36 \pm 2 \mathrm{pg} / \mathrm{mg}$; $n=6)$ compared with those of normal mice (5-HIAA, $220 \pm 8 \mathrm{pg} / \mathrm{mg} ; n=6$ ). $B$, $C, 5-\mathrm{HT}$ immunostaining in MAOA KO (P6) shows accumulation in the dLGN and VB $(B)$, as well as in retinal fibers $(C)$ and somatosensory thalamocortical fibers $(B) . D, E$, Excess 5-HT accumulation in the thalamus and thalamocortical fibers is identical in MAOA/5-HT1B DKO mice and MAOA KO mice. Furthermore, 5-HT immunostaining reveals the ipsilateral patch of retinal terminals in MAOA/ 5-HT1B DKO mice ( $E$, white arrows), whereas this is not visible in MAOA KO mice $(C)$. Abbreviations are as in Figure 2. Scale bar: $B, D, 0.4 \mathrm{~mm} ; C, E, 0.2 \mathrm{~mm}$.
In MAOA/5-HTT/5-HT1B triple knock-out (TKO) mice examined at P30 $(n=2)$, RGC projections had a normal eyespecific segregation (Fig. 3I,J) compared with the MAOA/5HTT DKO (Fig. 1E,F), despite the fact that extracellular levels of 5-HT in TKO mice could be more elevated than in MAOA/ 5-HT1B DKO mice (as suggested by increased 5-HT immunoreactivity in catecholaminergic neurons; data not shown).

The 5-HT1B receptor appears to be an important target of 5-HT in mediating the developmental changes of the retinal projections in MAOA KO and MAOA/5-HTT DKO mice.

\section{Somatosensory system: thalamocortical projections in MAOA KO mice}

Sensory hairs of the rodent's body surface have an isomorphic representation in the CNS. In the somatosensory cortex (S1), ventrobasal thalamic afferents segregate into whisker-specific domains called barrels (Figs. 5A, 6A). This pattern emerges be- tween P2 and P4 (Senft and Woolsey, 1991; Agmon et al., 1993; Catalano et al., 1996). Whisker-specific clusters of thalamic afferents become surrounded by cell aggregates forming the barrel walls, and after P4, cell-poor septa appear between barrel walls (Rice and Van der Loos, 1977). We analyzed the barrel field on complete series of tangential sections of the flattened hemispheres with 5-HTT immunochemistry, cytochrome oxidase (CO), and Nissl staining. 5-HTT immunochemistry mainly labels the thalamocortical fibers in the mouse cerebral cortex during the first postnatal week (Lebrand et al., 1998). In 129/Sv mice compared with $\mathrm{C} 3 \mathrm{H} / \mathrm{He}$ mice, $\mathrm{CO}$ barrels are less contrasted (data not shown), and septa between barrel walls in Nissl stains are less distinct (Fig. $8 H$, see legend).

In MAOA $\mathrm{KO}$ mice with a $\mathrm{C} 3 \mathrm{H} / \mathrm{He}$ background, thalamocortical fibers do not segregate into barrels (Cases et al., 1996), but PCPA treatment from P0 to P3 allows barrel formation. Because our previous studies had indicated that MAOA deficiency can 

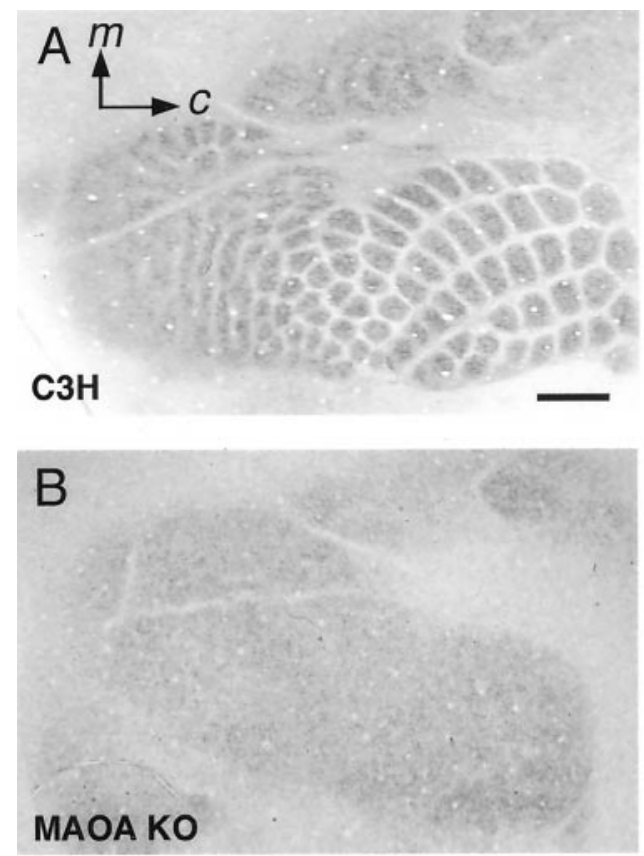

Similar alterations in the somatosensory systems of MAOA KO mice and MAOA/5-HTT DKO mice. $A-C$, Normal barrel field in (P8) $\mathrm{C} 3 \mathrm{H}$ mice revealed by $\mathrm{CO}$-staining on a tangential section through layer IV $(A)$. Barrel-less phenotype of (P8) MAOA KO mice $(B)$ and (P10) MAOA/5-HTT DKO mice (C). Genetic backgrounds are as indicated in the legend to Figure 1. $D-F$, Normal barreloids in $\mathrm{P} 7 \mathrm{C} 3 \mathrm{H}$ mice $(D)$. Large barreloids of the VB appear to be close to normal in P7 MAOA KO mice $(E)$ and P7 MAOA/5-HTT DKO mice $(F)$. However, the small medioventral barreloids corresponding to the AS vibrissae are not delineated (arrow). Scale bar: $A-C, 0.5$ $\mathrm{mm} ; D-F, 0.125 \mathrm{~mm}$.

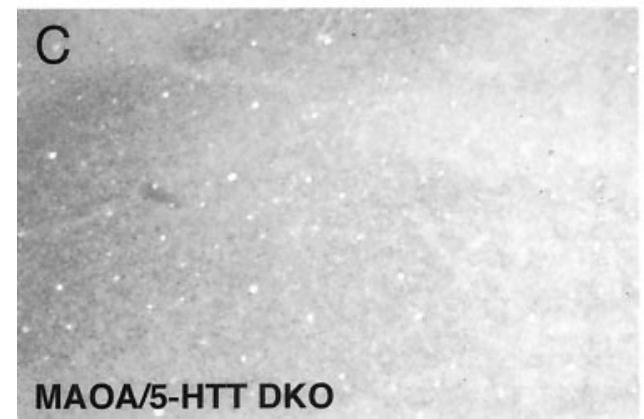

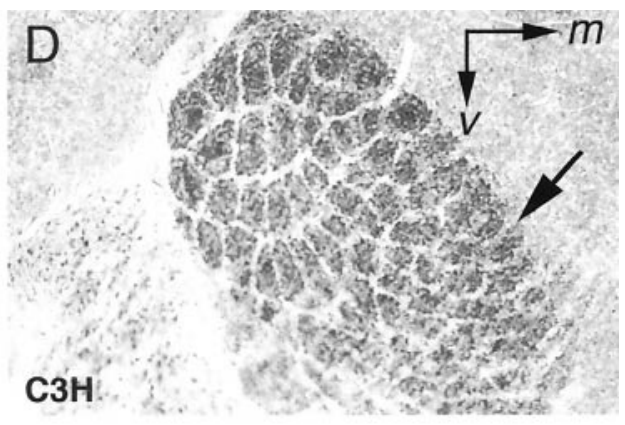

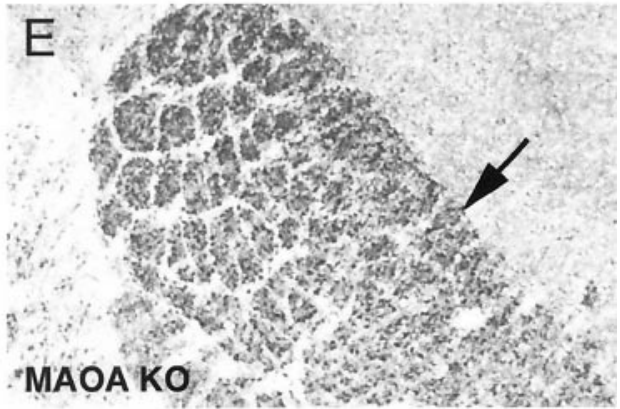

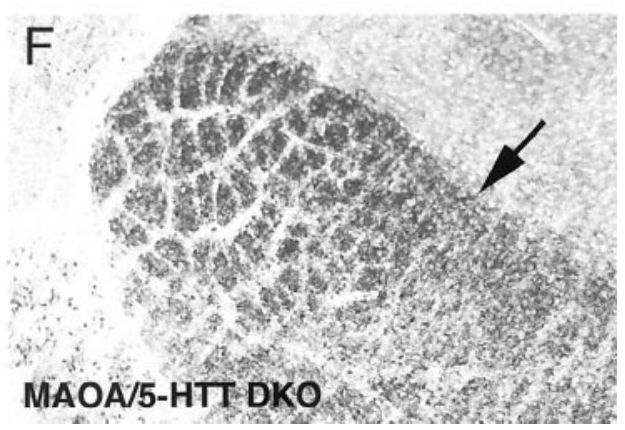

have slightly different effects on the barrel field development in different wild-type genetic backgrounds (Vitalis et al., 1998), we controlled for the effects of introducing the 129/Sv background (the background of the original 5-HT1B KO strain) on barrel development. In MAOA KO mice with a C3H/129 F1 hybrid background $(n=22)$, the most caudal barrels of the posteromedial barrel subfield (PMBSF) were present but abnormal (Fig. $6 B$ and legend for a minimally affected case). In MAOA KO mice with a $\mathrm{C} 3 \mathrm{H} / 129$ heterogeneous background $(n=25$; Fig. $5 B)$ and in 129-backcrossed MAOA KO mice ( $n=3$; data not shown), there was a complete barrel-less phenotype throughout S1.

As described for the visual system, we examined two mechanisms whereby 5-HT could exert its effects: via 5-HTT and via the 5-HT1B receptor.

\section{Somatosensory system: effects of removing the 5-HTT gene in MAOA KO mice}

5-HTT is transiently expressed in somatosensory relay neurons of the trigeminal nucleus and the ventrobasal thalamus (VB) during the critical period of barrel field development (Lebrand et al., 1996; Cases et al., 1998; Hansson et al., 1998). In normal mice, 5-HT is detected in thalamocortical terminals, whereas in MAOA KO mice, 5-HT accumulates all along the VB neurons (Fig. 4B,C) (Cases et al., 1998). We examined whether massive uptake and accumulation of 5-HT in the VB neurons play a role in the lack of barrels in MAOA KO mice, using the MAOA/5-HTT DKO mice.

In MAOA/5-HTT DKO mice, 5-HT immunocytochemistry showed no staining of the somatosensory thalamocortical projections in $\mathrm{S} 1$ but only scattered varicose fibers (Fig. $2 E, G$ ) compared with MAOA KO (Fig. 2B,D), confirming that the dense 5-HT labeling in the barrel field is attributable to uptake via 5-HTT. As examined with CO (Fig. 5C) and Nissl staining on both tangential and coronal sections of the cerebral cortex, we observed no patterned organization in layer IV from P7 to adulthood $(n=12)$. Because the abnormalities in S1 could be attributable to the lack of segregation of trigeminal afferents in the VB, we investigated the barreloids in the thalamus. We found that in P5 and P7 MAOA/5-HTT DKO mice $(n=5)$, the barreloids that represent the large mystacial vibrissae and project to the PMBSF are normally patterned (Fig. $5 F$ ), as previously described in the MAOA KO mice (Cases et al., 1996). However, the smallest barreloids corresponding to the hair (small vibrissae) on the anterior snout (AS) are blurred or absent in both the MAOA KO (Fig. $5 E$ ) and the MAOA/5-HTT DKO mice (Fig. $5 F$ ).

These observations in MAOA/5-HTT DKO mice suggest that extracellular increases of 5-HT are an important factor for exerting the effects of 5-HT on somatosensory thalamocortical segregation. This interpretation is supported by the observations of Persico and collaborators in 5-HTT KO mice, showing that the formation of the barrel field is altered and can be rescued by early treatment with PCPA (A. M. Persico, A. Baldi, E. Calia, R. Mössner, K. P. Lesch, D. L. Murphy, and F. Feller, personal communication). We confirmed these findings 

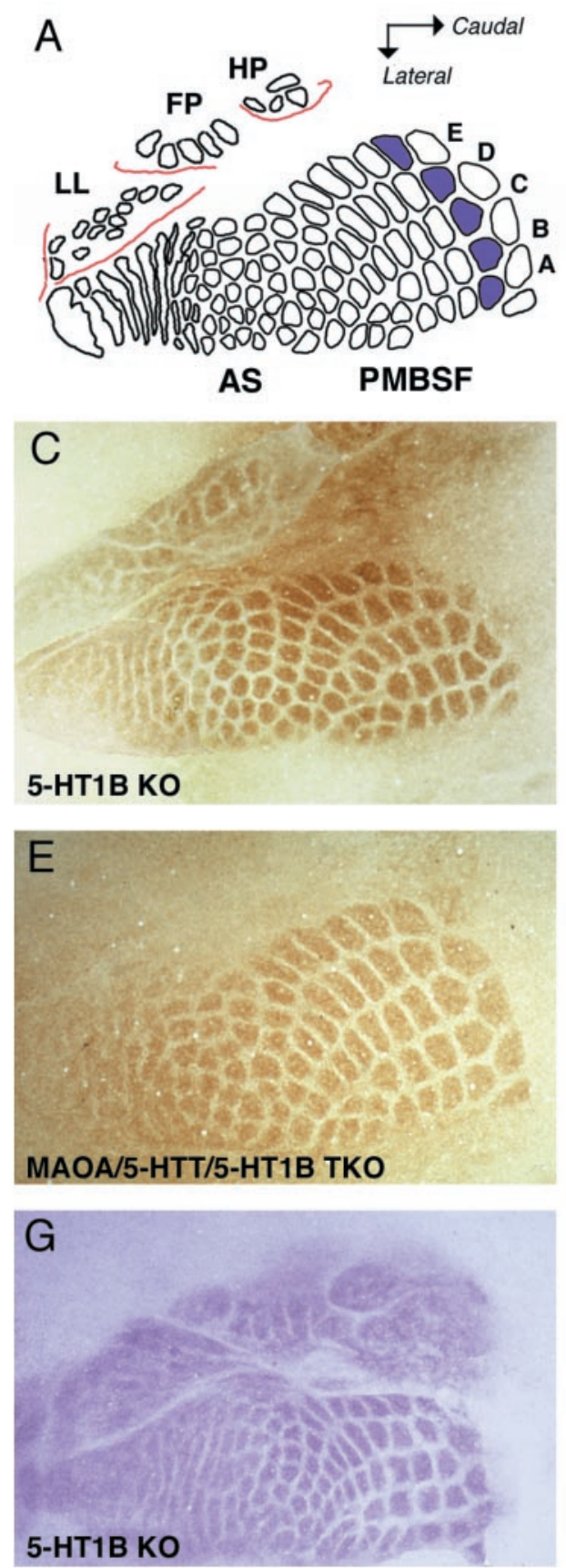
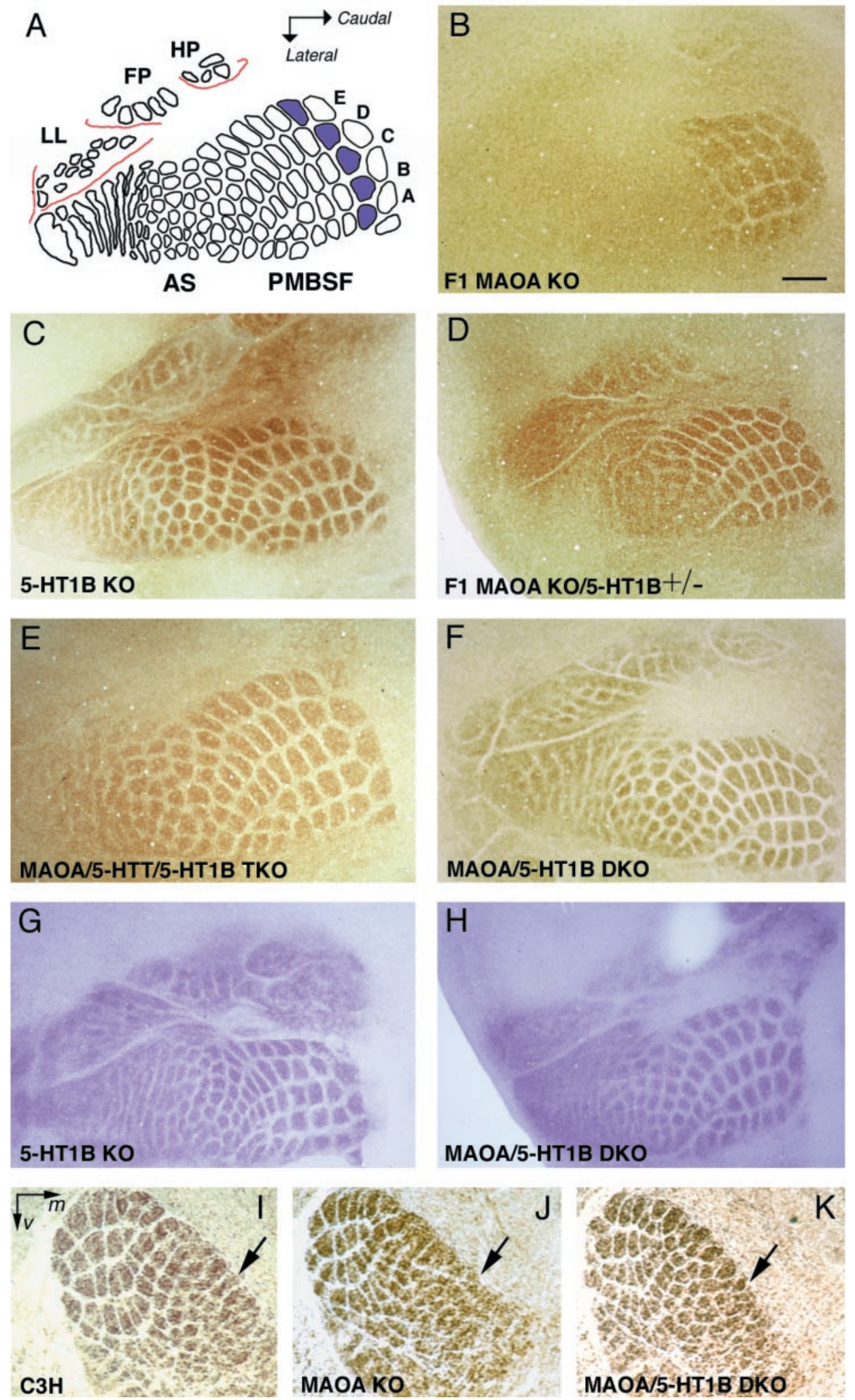

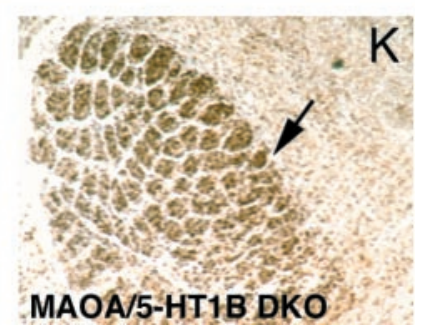

Figure 6. Effects of removing the 5-HT1B receptors on the cortical and thalamic somatosensory maps in normal mice, MAOA KO mice, and MAOA/5-HTT DKO mice. $A$, Scheme of a normal barrel field showing the different subfields: the posteromedial barrel subfield $(P M B S F)$, anterior snout $(A S)$, forepaw $(F P)$, lower lip $(L L)$, and hindpaw $(H P)$. The first barrels of the five rows $(A-E)$ of large whiskers are colored. $B-F, \mathrm{CO}$ histochemistry on tangential $40 \mu \mathrm{m}$ sections from P8-P12 flattened hemispheres. $B$, In the barrel field of (P9) F1 MAOA KO mice, some patterning is visible in the PMBSF, particularly in row $\mathrm{B}$. However, these barrels have a blurred aspect and are visible on a single section instead of two or three sections per hemisphere in normal mice. $C$, Normal barrel field in (P8) 5-HT1B KO mice (129 genetic background). $D$, F1 MAOA KO/5-HT1B+/- mice display normal barrels in the PMBSF, whereas small barrels in the AS are missing (P9). E, Normal barrel field in (P12) MAOA/5-HTT/5-HT1B TKO mice. $F$, Normal barrel field in $\mathrm{P} 8$ MAOA/5-HT1B DKO mice. $G, H, 5$-HTT immunostaining shows that thalamocortical patterning is normal in P6 5-HT1B KO mice $(G)$ and P6 MAOA/5-HT1B DKO mice $(H)$. $I-K$, Normal patterning in the thalamus of MAOA/5-HT1B DKO mice. I, Normal barreloids in $\mathrm{P} 5 \mathrm{C} 3 \mathrm{H}$ mice. $J$, Abnormal smallest barreloids in P5 MAOA KO mice. $K$, Normal barreloids in P5 MAOA/5-HT1B DKO mice. Scale bar: $B-H, 0.5 \mathrm{~mm} ; I-K, 0.19 \mathrm{~mm}$. in the 5-HTT KO mice generated in the present study: alterations were less severe than in MAOA KO mice, with a variable phenotype in the PMBSF (from normal to almost barrel-less) and the AS (barrels blurred or absent). Thus, as in the visual system, the results point to a role of 5-HT receptors carried on the cell surface.

\section{Somatosensory system: effects of removing the 5- HT1B receptor in MAOA-KO, 5-HTT KO mice, and MAOA/5-HTT DKO mice}

Thalamocortical fibers express 5-HT1B receptors during development (Bennett-Clarke et al., 1993; Cases et al., 1996). We examined mice lacking one or both alleles of this receptor in 
conditions of normal 5-HT levels (in 5-HT1B KO mice) or of increased extracellular 5-HT levels (in 5-HTT/5-HT1B DKO mice, in MAOA $\mathrm{KO} / 5-\mathrm{HT} 1 \mathrm{~B}+/-$ mice, in MAOA/5-HT1B DKO mice, and in MAOA/5-HTT/5-HT1B TKO mice).

As demonstrated with $\mathrm{CO}$ histochemistry and 5-HTT immunostaining, the barrel field of the 5-HT1B KO mice (Fig. 6C,G) was identical to that of the wild-type $129 / \mathrm{Sv}$ mice. Thus, 5-HT1B receptors are not essential for the establishment of the barrel field.

In MAOA KO mice lacking a single allele of the 5-HT1B gene and having a $\mathrm{C} 3 \mathrm{H} / 129 \mathrm{~F} 1$ hybrid background $(n=14$; from $\mathrm{P} 9$ to P25), the main barrels of the PMBSF became clearly delineated (Fig. 6D) and appear significantly different from the control F1 MAOA KO (Fig. 6B). Nevertheless, the segregation was incomplete, particularly in the AS. A similar pattern of barrels was observed in MAOA KO mice lacking a single allele of the 5-HT1B gene and having a $\mathrm{C} 3 \mathrm{H}$-enriched background $(n=3$; data not shown).

In contrast, in MAOA/5-HT1B DKO mice examined from P7 up to 2 years $(n=55)$, the entirety of the barrel field appeared restored in the majority of cases $(n=32)$. In CO-stained preparations reconstructed in the tangential plane, barrels were observed throughout the PMBSF, in the AS, lower lip, and forepaw representations (Fig. $6 F$ ). The normal clustering of the thalamocortical projections was confirmed by 5 -HTT immunostaining at P6, showing a clear delimitation of barrels throughout S1 (Fig. $6 H)$. In the other MAOA/5-HT1B DKO mice $(n=23)$, the major part of the barrel field was normal, except for the AS field in which barrels tended to be blurred. In the thalamus, MAOA/ 5-HT1B DKO mice displayed a normal organization of the barreloids ( $n=3$ at P5), including the AS field (Fig. $6 K$ ) that is defective in the MAOA KO (Fig. $6 J$ ). As already mentioned, the lack of 5-HT1B receptors caused no detectable modification of 5-HT levels in the MAOA KO mice (Fig. 4A). 5-HT immunocytochemistry showed a very intense labeling of the somatosensory thalamocortical fibers of MAOA/5-HT1B DKO mice, indicating that 5-HT continues to be taken up and accumulated in these neurons (Fig. 4D).

In 5-HTT KO mice and in MAOA/5-HTT DKO mice, we demonstrated a similar effect of the 5-HT1B gene. A normal pattern of barrels was observed in the 5-HTT/5-HT1B DKO mice (data not shown) and in the MAOA/5-HTT/5-HT1B TKO mice (Fig. $6 E$ ). This was essentially analyzed with CO staining $(n=8)$, using 5-HTT KO and MAOA/5-HTT DKO pups from the same litter as controls.

The alterations of cortical and thalamic maps in MAOA KO mice could explain some of their behavioral abnormalities (Cases et al., 1995). When adult MAOA KO mice with a $\mathrm{C} 3 \mathrm{H}$ background are placed on a narrow beam, they cross the beam at normal speed, but contrary to normal mice, they crawl rather than walk (Fig. 7). This is not directly related to a visual processing defect because $\mathrm{C} 3 \mathrm{H}$ mice carry a retinal degeneration gene, and all adult mice (wild-type and MAOA KO) are blind. To determine whether this behavioral defect of MAOA KO mice has a 5-HT developmental component, MAOA KO pups were treated with the inhibitor of 5 -HT synthesis PCPA $\left(300 \mathrm{mg} \cdot \mathrm{kg}^{-1} \cdot \mathrm{d}^{-1}\right.$; $n=16$ ) from birth to P14. PCPA treatment greatly improved their walking posture on the beam as adults. On the other hand, untreated MAOA/5-HT1B DKO walked normally on the beam. These experiments indicate that removing the 5-HT1B receptor prevents a behavioral deficit that depends on excess 5-HT during

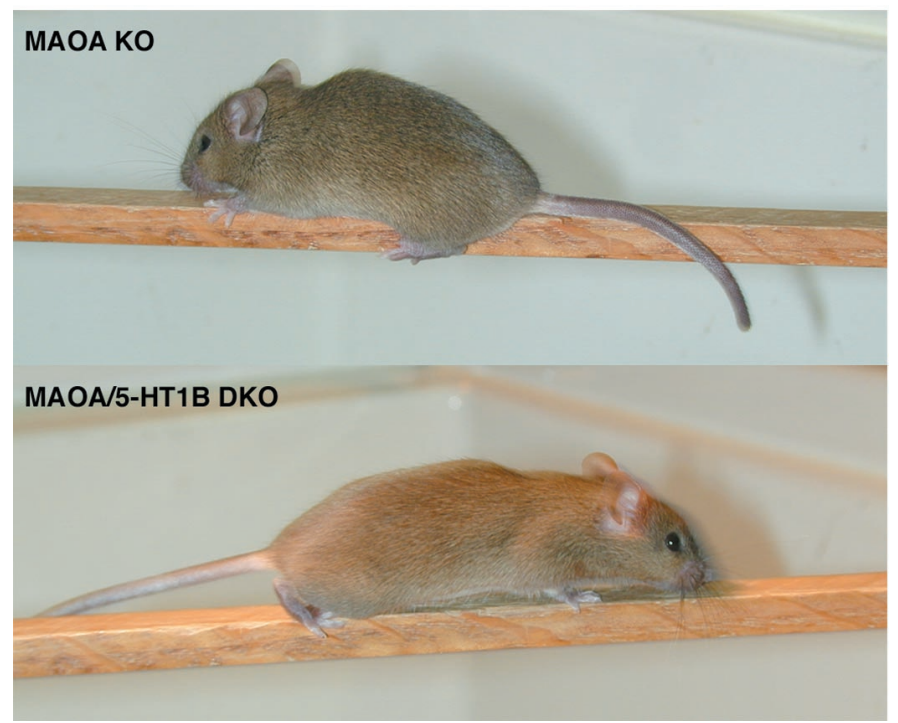

Figure 7. Removal of the 5-HT1B receptor restores normal beamwalking ability in MAOA KO mice. When placed on a narrow beam, MAOA KO mice with a $\mathrm{C} 3 \mathrm{H}$ background crawl rather than walk, with hindlimbs grasping the beam, whereas MAOA/5HT1B DKO mice walk as $\mathrm{C} 3 \mathrm{H}$ control mice (MAOA KO mice walk normally on slightly larger beams). The different coat color of the DKO mouse is an artifact.

development and that is likely to have a somatosensory component.

\section{Somatosensory system: persistent cytoarchitectonic abnormalities of cortical neurons in the MAOA/5-HT1B DKO and MAOA/5-HTT/5-HT1B TKO mice}

Despite the normal development of the barrel field when using stains that preferentially label thalamocortical projections, the purely cellular Nissl stains indicated that segregation of cortical cells of the barrel field was incomplete in the MAOA/5-HT1B DKO mice from P16 up to 1 year $(n=12)$. Indeed, all the MAOA/5-HT1B DKO mice analyzed had abnormalities of the barrels in the PMBSF: the barrel walls were thick, hollows were not clear, and septa were often absent (Fig. 8A, $C$ for a minimally affected case). These abnormalities were more apparent for the small barrels of the AS (Fig. $8 E, G$ ). Similar observations were made in Nissl stains from MAOA/5-HTT/5-HT1B TKO mice $(n=8)$. To test the hypothesis that the increase of 5-HT is responsible for these residual abnormalities, we treated MAOA/ 5-HT1B DKO mice $(n=6)$ with PCPA between P0 and P8 and examined their barrel field at P16. Control MAOA/5-HT1B DKO mice $(n=3)$ in the same litter were injected with water. We found that reducing 5-HT allows a normal segregation of cortical cells in the barrel field in both the PMBSF (Fig. $8 B, D$ ) and the AS (Fig. $8 F, H$ ). Thus, in MAOA/5-HT1B DKO and MAOA/5HTT/5-HT1B TKO mice, 5-HT in excess has deleterious effects on cortical cell organization in layer IV of S1.

\section{DISCUSSION}

Our genetic study demonstrates that an overactivation of the 5-HT1B receptors prevents the normal patterning of projections in both the visual (retinogeniculate) and the somatosensory (trigeminothalamic and thalamocortical) systems, with a gene-dosage effect in 5-HT1B receptor action. However, 5-HT1B receptors are not essential for the formation of these maps. 

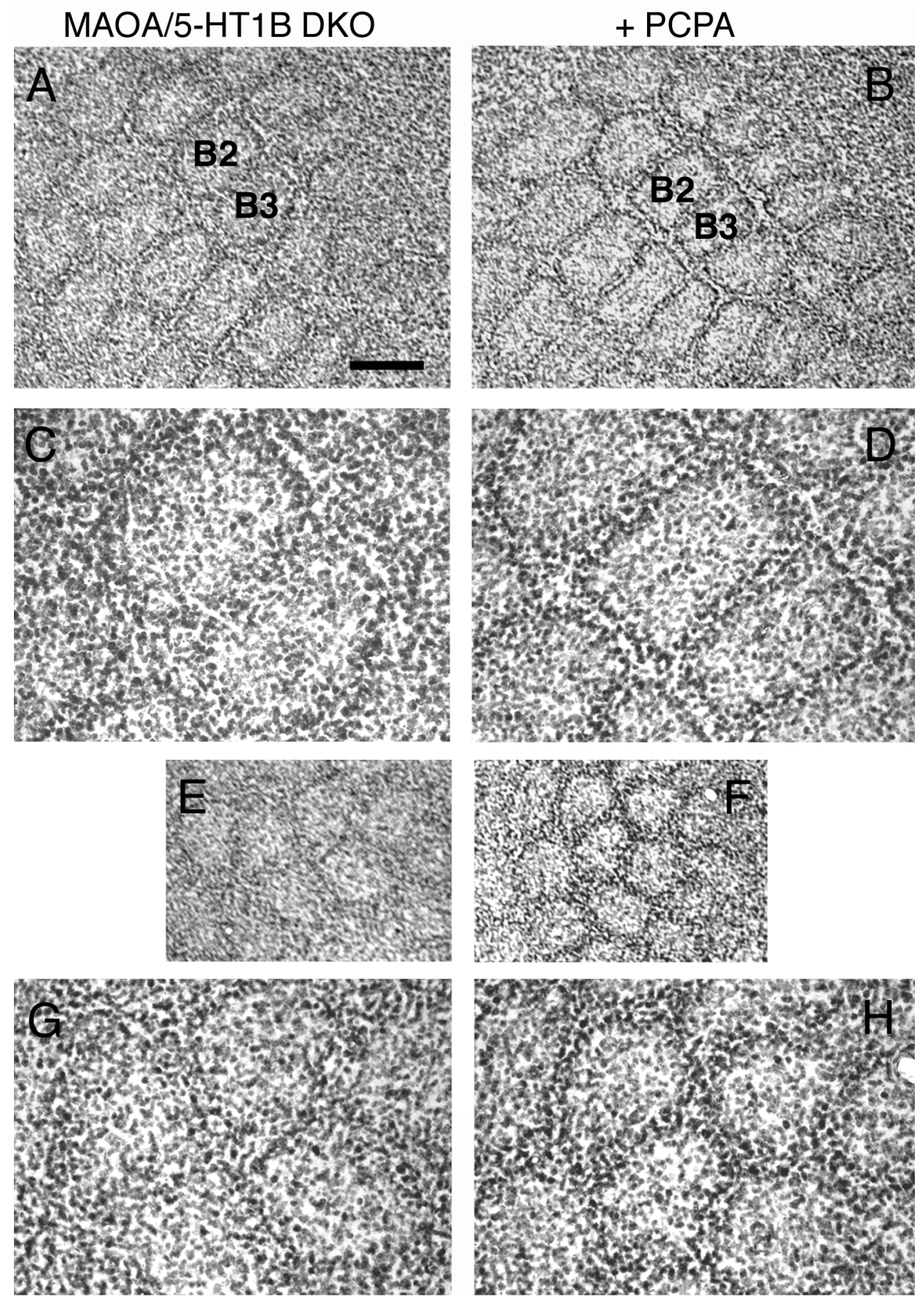

Figure 8. Incomplete segregation of the barrel cytoarchitecture in P16 MAOA/5-HT1B DKO mice. $A-H$, Lack of clear segregation of cortical cells in the PMBSF and AS of P16 MAOA/5-HT1B DKO mice compared with MAOA/5-HT1B DKO mice (from the same litter) treated with PCPA for P0-P8, to reduce 5-HT brain levels. $A-D$, PCPA-treated MAOA/5-HT1B DKO mice show a sharp pattern of cortical cells in the PMBSF barrels $(B)$ compared with untreated littermates $(A)$. The $\mathrm{B} 2$ and $\mathrm{B} 3$ barrels $(A, B)$ have been enlarged $(C, D)$ to show the normal distribution of cells in the treated mouse. $E-H$, Improved cortical cytoarchitecture in the AS of PCPA-treated MAOA/5-HT1B DKO mice $(F, H)$, compared with untreated littermates $(E$, $G)$. Nevertheless, the sides of neighboring barrels are not clearly separated by septa $(H)$. An absence of septa in this region was similarly observed in wild-type 129 mice and 5-HT1B KO mice (data not shown). Scale bar: $A, B, E, F, 0.3 \mathrm{~mm} C, D, G, H, 0.075 \mathrm{~mm}$.

\section{Abnormal patterning of the somatosensory and visual projections is not mediated by 5 -HT uptake}

One intriguing feature of the visual and somatosensory thalamocortical systems during development is that they express the plasmalemnal and vesicular transporters that allow 5-HT to be taken up in terminal axons and possibly be stored into vesicles (Lebrand et al., 1996, 1998; Hansson et al., 1998). 5-HT is detectable in the terminal fields of the somatosensory thalamic axons during a critical developmental period, P0-P10 in mice (Fujimiya et al., 1986; Lebrand et al., 1996) and in rats (Rhoades 
et al., 1990; Blue et al., 1991; Dori et al., 1996). Similarly 5-HT is transiently visible in ipsilateral retinogeniculate terminals (Upton et al., 1999).

We found that 5-HTT KO mice had alterations in the segregation of the ipsilateral-contralateral retinogeniculate projections that resembled those of the MAOA KO mice, although they were less severe. Similarly, in the somatosensory system, Persico and collaborators have found alterations in the formation of barrels in the rostral parts of the barrel field (A. Persico, personal communication), a finding that was confirmed in the present study on 5-HTT KO mice with a different genetic background. These barrel field abnormalities were mediated by the 5-HT1B receptor since they were corrected in the 5-HTT/5-HT1B DKO mice. This suggests that one important purpose of 5-HT uptake in this system is to clear 5-HT and prevent the saturation of the highaffinity 5-HT1B receptors.

It remained possible that the inappropriate internalization and accumulation of 5-HT in the RGCs and in the thalamic sensory neurons observed in the MAOA KO mice (Cases et al., 1998; Upton et al., 1999) could be the cause of developmental alterations in these systems. However, the present genetic study argues against this possibility by two observations: (1) MAOA KO mice display the same altered projection patterns when the 5-HTT gene is inactivated, and (2) in MAOA/5-HT1B DKO mice, somatosensory thalamocortical and retinogeniculate projection patterns are restored despite the continued massive accumulation of 5-HT in these pathways. These observations, together with the results in 5-HTT KO mice and MAOA/5-HTT/5-HT1B TKO mice, stress the disruptive effects of 5-HT build-up in the extracellular space.

\section{Role of the 5-HT1B receptor}

The effects of 5-HT1B receptor overactivation that we observed in the visual and somatosensory systems concern late stages of development, when axons begin to segregate into more restricted terminal fields in the wild-type mice (clustering into one barrel or clustering of the ipsilateral terminal axons), whereas they fail to do so in the MAOA KO mice.

The detailed localization of 5-HT1B receptors during development has not yet been described, but available reports indicate that in the developing rat cerebral cortex, 5-HT1B receptors (binding sites) are essentially localized on thalamic sensory axon terminals (Bennett-Clarke et al., 1993; Mansour-Robaey et al., 1998). Similarly, normal mouse pups display transient 5-HT1B labeling in the barrel field (Cases et al., 1996). This labeling is reduced in MAOA KO mice (Cases et al., 1996), which probably reflects overstimulation of 5 -HT1B receptors. In the visual system, it is known that developing retinal ganglion cells express transcripts for the 5-HT1B receptor (Upton et al., 1999). Studies in adult rodents showed that the 5 -HT1B protein is expressed in RGCs but is distributed exclusively in the axonal compartment, essentially in preterminal retinal axons (Boschert et al., 1994; Boulenguez, 1996; Pickard et al., 1999; Sari et al., 1999; and for other systems, Riad et al., 2000). Thus, in both sensory systems current evidence stresses the main presynaptic localization of the 5-HT1B receptors.

The 5-HT1B receptor is known to inhibit transmitter release in various systems during development and adult life. Particularly relevant to the present study, there is some electrophysiological evidence that stimulation of the 5-HT1B receptor reduces excitatory neurotransmission in the thalamocortical as in the retinotectal and retinohypothalamic systems (Mooney et al., 1994;
Rhoades et al., 1994; Pickard et al., 1999). This physiological role of 5-HT1B receptors could explain the lack of segregation in MAOA KO mice. This hypothesis will be discussed in the next section.

5-HT1B activation may also cause direct trophic stimulation of ingrowing thalamocortical fibers because 5-HT and the 5-HT1B agonist CGS-12066A enhance neurite outgrowth in primary thalamic cultures (Lieske et al., 1999; Lotto et al., 1999). Comparatively, treatments that reduce 5-HT levels in the developing cortex (Rhoades et al., 1998; but see Persico et al., 2000) cause a reduction in barrel size, suggesting a reduced growth of thalamocortical axonal arbors.

5-HT1B receptors are coupled to GTP-binding regulatory proteins $G_{i} / G_{o}$ that have been shown to modulate adenylyl cyclase activity, stimulate inositol phospholipid hydrolysis, and promote the opening of potassium channels and closing of voltagesensitive calcium channels (for review, see Boess and Martin, 1994; Morris and Malbon, 1999), each of these pathways being possibly important in effecting the developmental changes presently observed.

Whereas a large part of the effects of increased 5-HT is mediated by the 5-HT1B receptor, the complete absence of this receptor has no visible effects on the patterning of thalamocortical or retinogeniculate projections, at least with the $129 / \mathrm{Sv}$ genetic background. Several nonexclusive hypotheses can be considered to explain these results: (1) the 5-HT1B receptor is not implicated in the establishment of these projections (yet when the 5-HT1B mutation was backcrossed onto the $\mathrm{C} 3 \mathrm{H} / \mathrm{He}$ strain background, barrels of congenics did not appear as sharp as those of $\mathrm{C} 3 \mathrm{H} / \mathrm{He}$ mice; unpublished data); (2) compensatory mechanisms take place in the 5-HT1B KO mice; (3) the absence of the 5-HT1B receptor results in a functional perturbation that is not detectable at our level of analysis, and (4) the 5-HT1B receptor plays a role in the establishment of different retinal and somatosensory thalamic projections.

Two speculations can be made on possible combined actions of the 5-HT1B receptor and 5-HTT in the normal situation. Internalized 5-HT in sensory projections could be used as a cotransmitter of glutamate and act locally to stimulate 5-HT1B receptors, providing a negative control of glutamate release. In addition, stimulation of 5-HT1B receptors on neighboring axons could enhance the competition between appropriately and inappropriately located projections: axons located within inappropriate barrels or eye-specific domains could be more frequently exposed to inhibitory levels of 5-HT because of their lower abundance or because of a lack of 5-HTT (leading to reduced clearance of 5-HT) as in the case of contralateral retinal axons in the ipsilateral territory of the dLGN.

\section{Activity-driven mechanisms in retinogeniculate and barrel field development}

In the visual system, the neural activity has been shown to shape the retinal terminal arbors and the dendrites of retino-recipient neurons (Shatz and Stryker, 1988; Constantine-Paton et al., 1990; Shatz, 1996). This effect is independent of patterned vision because it occurs before the opening of the eyes and is underlain by waves of neural activity that are generated in the amacrine and ganglion cells of the retina (Galli and Maffei, 1988; Mooney et al., 1996; Feller et al., 1997; Penn et al., 1998; Wong, 1999). However recent experimental evidence has raised doubts concerning the role of activity in visual pattern formation, because TTX implants into the ferret eye delayed but did not completely eliminate 
eye-specific segregation (Cook et al., 1999), and crude ocular dominance patterns of thalamocortical projections emerged in the absence of retinal inputs (Crowley and Katz, 1999). Our present observations in MAOA KO and 5-HTT KO mice suggest that overstimulation of 5-HT1B receptors could interfere with the transmission of spontaneous neural activity either by blocking the generation of spontaneous activity in the retina or by blocking the transmission of this activity to the visual centers. 5-HT could prevent the generation of spontaneous slow waves of activity in the retina by reducing cAMP levels (Stellwagen et al., 1999). However, because 5-HT1B receptors are located in preterminal retinotectal projections and inhibit glutamatergic neurotransmission (Mooney et al., 1994), the most likely mechanism is that excessive 5-HT1B receptor stimulation blocks the propagation of the neural activity generated in the retina to the dLGN.

In the primary somatosensory cortex, the role of neural activity in the formation of the barrels is even more controversial (Chiaia et al., 1992, 1994a,b; Schlaggar et al., 1993; Killackey et al., 1995; Fox et al., 1996; Mitrovic et al., 1996; Iwasato et al., 1997; Rhoades et al., 1998). We show here that alterations are visible in the small barreloids of MAOA KO mice and MAOA/5-HTT DKO mice and that no patterning develops in the primary somatosensory cortex of these mutants. Both types of effects depend on 5-HT1B receptor activation because they are both reversed in the MAOA/5-HT1B DKO mice. This suggests that 5-HT in the extracellular space acts at least at two levels on the trigeminal pathway: in the trigeminothalamic and in the thalamocortical projections. Alternatively, altered neurotransmission in the brainstem or thalamus could cause reduced activity of thalamic neurons and suffice to prevent the clustering of thalamocortical afferents.

Using thalamocortical slice preparations from rats aged P6P10, Rhoades et al. (1994) demonstrated that 5-HT applications reduced glutamatergic responses of S1 neurons after VB stimulation. This effect was mimicked by the 5-HT1B receptor agonist CGS12066B and declined after P10 (Rhoades et al., 1994), which is concordant with the transient presence 5-HT1B receptors in VB neurons (Bennett-Clarke et al., 1993; Cases et al., 1996). Thus, in 5-HTT KO mice and MAOA KO mice, excess of 5-HT1B receptor stimulation could prevent activity-dependent processes involved in the patterning of afferents. The phenotype of these mice could be rescued by facilitating glutamatergic transmission, either pharmacologically or genetically (e.g., using glutamate transporter knock-outs instead of 5-HT1B KO mice).

\section{Postsynaptic effects of 5-HT in the barrel field}

The absence of 5-HT1B receptors never entirely prevented the cytoarchitectonic alterations in the barrel field of the MAOA KO mice: the layout of neurons as barrels with a ring of densely packed cells surrounding a hollow with lower cell density was not as sharp as in controls. This organization is dependent on a specific distribution of the neurons in layer IV that maintain their dendritic arbor within the confines of one barrel (Harris and Woolsey, 1983). Apical dendrites of infragranular neurons form organized bundles coursing in the septa between barrels. Because in MAOA/5-HT1B DKO mice, most of the residual cytoarchitectural abnormalities were corrected by an early treatment with PCPA that normalized 5-HT brain levels at critical developmental times, this suggests that 5-HT also has a direct effect on the maturation of cortical target neurons in layer IV, via some other receptor than the 5-HT1B receptor. No 5-HT receptors have been identified unambiguously in the spiny stellate neurons of layer IV, but binding studies using the 5-HT2 receptor agonist DOI have shown the presence of a transient dense 5-HT2 labeling in the barrels (Mansour-Robaey et al., 1998), and immunocytochemical analyses suggested the presence of 5-HT2A receptors in the dendrites of pyramidal cells (Cornea-Hebert et al., 1999).

In conclusion, we show that excessive stimulation of the 5-HT1B receptors induces alterations in the segregation of axons in three sensory pathways: the retinogeniculate projections, the somatosensory projections to the thalamus, and the thalamic projections to the barrel field cortex. Because the 5-HT1B receptors are known to mediate presynaptic inhibition of excitatory neurotransmission, our results support the idea that segregation of both visual and somatosensory afferents is an activitydependent process. Whatever the physiological mechanisms involved, this is the first example of presynaptic "inhibitory" receptors that can permanently alter brain architecture when they are overstimulated during a critical developmental period. Other neural connections may be comparably affected by overactivation of 5-HT1B receptors, such as hippocampal efferent pathways or thalamocortical afferents to the prefrontal cortex, because they express 5-HT1B transcripts during development (C. Lebrand and P. Gaspar, unpublished observations). Our behavioral findings indicate that 5-HT1B receptor overactivation during early life can account for, or at least contribute to behavioral deficits in adult life.

\section{REFERENCES}

Adams JC (1980) Stabilizing and rapid thionin staining of TMB-based HRP reaction product. Neurosci Lett 17:7-9.

Agmon A, Yang LT, O’Dowd DK, Jones EG (1993) Organized growth of thalamocortical axons from the deep tier of terminations into layer IV of developing mouse barrel cortex. J Neurosci 13:5365-5382.

Bengel D, Murphy DL, Andrews AM, Wichems CH, Feltner D, Heils A, Mössner R, Westphal H, Lesch KP (1998) Altered brain serotonin homeostasis and locomotor insensitivity to 3,4-methylenedioxymethamphetamine ("Ecstasy") in serotonin transporter-deficient mice. Mol Pharmacol 53:649-655.

Bennett-Clarke CA, Leslie MJ, Chiaia NL, Rhoades RW (1993) Serotonin $1 \mathrm{~B}$ receptors in the developing somatosensory and visual cortices are located on thalamocortical axons. Proc Natl Acad Sci USA 90:153-157.

Bennett-Clarke CA, Chiaia NL, Rhoades RW (1996) Thalamocortical afferents in rat transiently express high-affinity serotonin uptake sites. Brain Res 733:301-306.

Blue ME, Erzurumlu RS, Jhaveri S (1991) A comparison of pattern formation by thalamocortical and serotonergic afferents in the rat barrel field cortex. Cereb Cortex 1:380-389.

Boess FG, Martin IL (1994) Molecular biology of 5-HT receptors. Neuropharmacology 33:275-317.

Boschert U, Amara DA, Segu L, Hen R (1994) The mouse 5-hydroxytryptamine1B receptor is localized predominantly on axon terminals. Neuroscience 58:167-182.

Boulenguez P, Pinard R, Segu L (1996) Subcellular localization of 5-HT1B binding sites in the stratum griseum superficiale of the rat superior colliculus: an electron microscopic quantitative autoradiographic study. Synapse 24:203-212.

Brunner HG, Nelen M, Breakefield XO, Ropers HH, van Oost BA (1993) Abnormal behavior associated with a point mutation in the structural gene for monoamine oxidase A. Science 262:578-580.

Cases O, Seif I, Grimsby J, Gaspar P, Chen K, Pournin S, Müller U, Aguet M, Babinet C, Shih JC, De Maeyer E (1995) Aggressive behavior and altered amounts of brain serotonin and norepinephrine in mice lacking MAOA. Science 268:1763-1766.

Cases O, Vitalis T, Seif I, De Maeyer E, Sotelo C, Gaspar P (1996) Lack of barrels in the somatosensory cortex of monoamine oxidase A-deficient mice: role of a serotonin excess during the critical period. Neuron 16:297-307.

Cases O, Lebrand C, Giros B, Vitalis T, De Maeyer E, Caron MG, Price DJ, Gaspar P, Seif I (1998) Plasma membrane transporters of serotonin, dopamine, and norepinephrine mediate serotonin accumulation in atypical locations in the developing brain of monoamine oxidase A knock-outs. J Neurosci 18:6914-6927.

Catalano SM, Robertson RT, Killackey HP (1996) Individual axon morphology and thalamocortical topography in developing rat somatosensory cortex. J Comp Neurol 367:36-53. 
Chiaia NL, Fish SE, Bauer WR, Bennett-Clarke CA, Rhoades RW (1992) Postnatal blockade of cortical activity by tetrodotoxin does not disrupt the formation of vibrissa-related patterns in the rat's somatosensory cortex. Dev Brain Res 66:244-250.

Chiaia NL, Fish SE, Bauer WR, Figley BA, Eck M, Bennett-Clarke CA, Rhoades RW (1994a) Effects of postnatal blockage of cortical activity with tetrodotoxin upon lesion-induced reorganization of vibrissaerelated patterns in the somatosensory cortex of rat. Dev Brain Res 79:301-306.

Chiaia NL, Fish SE, Bauer WR, Figley BA, Eck M, Bennett-Clarke CA, Rhoades RW (1994b) Effects of postnatal blockade of cortical activity with tetrodotoxin upon the development and plasticity of vibrissarelated patterns in the somatosensory cortex of hamsters. Somatosens Mot Res 11:219-228.

Collins FA, Murphy DL, Reiss AL, Sims KB, Lewis JG, Freund L, Karoum F, Zhu D, Maumenee IH, Antonarakis SE (1992) Clinical, biochemical, and neuropsychiatric evaluation of a patient with a contiguous gene syndrome due to a microdeletion Xp11.3 including the Norrie disease locus and monoamine oxidase (MAOA and MAOB) genes. Am J Med Genet 42:127-134.

Constantine-Paton M, Cline HT, Debski E (1990) Patterned activity, synaptic convergence, and the NMDA receptor in developing visual pathways. Annu Rev Neurosci 13:129-154.

Cook PM, Prusky G, Ramoa AS (1999) The role of spontaneous retinal activity before eye opening in the maturation of form and function in the retinogeniculate pathway of the ferret. Vis Neurosci 16:491-501.

Cornea-Hebert V, Riad M, Wu C, Singh SK, Descarries L (1999) Cellular and subcellular distribution of the serotonin 5-HT2A receptor in the central nervous system of adult rat. J Comp Neurol 409:187-209.

Crowley JC, Katz LC (1999) Development of ocular dominance columns in the absence of retinal input. Nat Neurosci 2:1125-1130.

Dori I, Dinopoulos A, Blue ME, Parnavelas JG (1996) Regional differences in the ontogeny of the serotonergic projection to the cerebral cortex. Exp Neurol 138:1-14.

Dräger UC, Olsen JF (1980) Origins of crossed and uncrossed retinal projections in pigmented and albino mice. J Comp Neurol 191:383-412.

Feldman DE, Nicoll RA, Malenka RC (1999) Synaptic plasticity at thalamocortical synapses in developing rat somatosensory cortex: LTP, LTD, and silent synapses. J Neurobiol 41:92-101.

Feller MB, Butts DA, Aaron HL, Rokhsar DS, Shatz CJ (1997) Dynamic processes shape spatiotemporal properties of retinal waves. Neuron 19:293-306.

Fox K, Schlaggar BL, Glazewski S, O’Leary DD (1996) Glutamate receptor blockade at cortical synapses disrupts development of thalamocortical and columnar organization in somatosensory cortex. Proc Natl Acad Sci USA 93:5584-5589.

Fujimiya M, Kimura H, Maeda T (1986) Postnatal development of serotonin nerve fibers in the somatosensory cortex of mice studied by immunohistochemistry. J Comp Neurol 246:191-201.

Galli L, Maffei L (1988) Spontaneous impulse activity of rat retinal ganglion cells in prenatal life. Science 242:90-91.

Godement P, Salaun J, Imbert M (1984) Prenatal and postnatal development of retinogeniculate and retinocollicular projections in the mouse. J Comp Neurol 230:552-575.

Hamon M, Fattaccini CM, Adrien J, Gallissot MC, Martin P, Gozlan H (1988) Alterations of central serotonin and dopamine turnover in rats treated with ipsapirone and other 5-hydroxytryptamine1A agonists with potential anxiolytic properties. J Pharmacol Exp Ther 246:745-752.

Hansson SR, Mezey E, Hoffman BJ (1998) Serotonin transporter messenger RNA in the developing rat brain: early expression in serotonergic neurons and transient expression in non serotonergic neurons. Neuroscience 83:1185-1201.

Harris RM, Woolsey TA (1983) Computer-assisted analyses of barrel neuron axons and their putative synaptic contacts. J Comp Neurol 220:63-79.

Hen R (1999) Testing the genetics of behavior in mice. Science 285:2068-2069.

Iwasato T, Erzurumlu RS, Huerta PT, Chen DF, Sasaoka T, Ulupinar E, Tonegawa S (1997) NMDA receptor-dependent refinement of somatotopic maps. Neuron 19:1201-1210.

Katz LC, Shatz CJ (1996) Synaptic activity and the construction of cortical circuits. Science 274:1133-1138.

Killackey HP, Rhoades RW, Bennett-Clarke CA (1995) The formation of a cortical somatotopic map. Trends Neurosci 18:402-407.

LaVail JH, Nixon RA, Sidman RL (1978) Genetic control of retinal ganglion cell projections. J Comp Neurol 182:399-421.

Lebrand C, Cases O, Adelbrecht C, Doye A, Alvarez C, El Mestikawy S, Seif I, Gaspar P (1996) Transient uptake and storage of serotonin in developing thalamic neurons. Neuron 17:823-835.

Lebrand C, Cases O, Wehrle R, Blakely RD, Edwards RH, Gaspar P (1998) Transient developmental expression of monoamine transporters in the rodent forebrain. J Comp Neurol 401:506-524.

Lieske V, Bennett-Clarke CA, Rhoades RW (1999) Effects of serotonin on neurite outgrowth from thalamic neurons in vitro. Neuroscience 90:967-974. Lotto B, Upton L, Price DJ, Gaspar P (1999) Serotonin receptor activation enhances neurite outgrowth of thalamic neurones in rodents. Neurosci Lett 269:87-90.

Mansour-Robaey S, Mechawar N, Radja F, Beaulieu C, Descarries L (1998) Quantified distribution of serotonin transporter and receptors during the postnatal development of the rat barrel field cortex. Dev Brain Res 107:159-163.

Mesulam MM, Hegarty E, Barbas H, Carson KA, Gower EC, Knapp AG, Moss MB, Mufson EJ (1980) Additional factors influencing sensitivity in the tetramethyl benzidine method for horseradish peroxidase neurohistochemistry. J Histochem Cytochem 28:1255-1259.

Mitrovic N, Mohajeri H, Schachner M (1996) Effects of NMDA receptor blockade in the developing rat somatosensory cortex on the expression of the glia-derived extracellular matrix glycoprotein tenascin-C. Eur J Neurosci 8:1793-1802.

Mooney RD, Shi MY, Rhoades RW (1994) Modulation of retinotectal transmission by presynaptic 5-HT1B receptors in the superior colliculus of the adult hamster. J Neurophysiol 72:3-13.

Mooney R, Penn AA, Gallego R, Shatz CJ (1996) Thalamic relay of spontaneous retinal activity prior to vision. Neuron 17:863-874.

Morris AJ, Malbon CC (1999) Physiological regulation of G proteinlinked signaling. Physiol Rev 79:1373-1430.

O'Leary DD, Ruff NL, Dyck RH (1994) Development, critical period plasticity, and adult reorganizations of mammalian somatosensory systems. Curr Opin Neurobiol 4:535-544.

Penn AA, Riquelme PA, Feller MB, Shatz CJ (1998) Competition in retinogeniculate patterning driven by spontaneous activity. Science 279:2108-2112.

Persico AM, Altamura C, Calia E, Puglisi-Allegra S, Ventura R, Lucchese F, Keller F (2000) Serotonin depletion and barrel cortex development: impact of growth impairment vs. serotonin effects on thalamocortical endings. Cereb Cortex 10:181-191.

Pickard GE, Smith BN, Belenky M, Rea MA, Dudek FE, Sollars PJ (1999) 5-HT1B receptor-mediated presynaptic inhibition of retinal input to the suprachiasmatic nucleus. J Neurosci 19:4034-4045.

Rhoades RW, Bennett-Clarke CA, Chiaia NL, White FA, MacDonald GJ, Haring JH, Jacquin MF (1990) Development and lesion induced reorganization of the cortical representation of the rat's body surface as revealed by immunochemistry for serotonin. J Comp Neurol 293:190-207

Rhoades RW, Bennett-Clarke CA, Shi MY, Mooney RD (1994) Effects of 5-HT on thalamocortical synaptic transmission in the developing rat. J Neurophysiol 72:2438-2450.

Rhoades RW, Chiaia NL, Lane RD, Bennett-Clarke CA (1998) Effect of activity blockade on changes in vibrissae-related patterns in the rat's primary somatosensory cortex induced by serotonin depletion. J Comp Neurol 402:276-283.

Riad M, Garcia S, Watkins KC, Jodoin N, Doucet E, Langlois X, El Mestikawy S, Hamon M, Descarries L (2000) Somatodendritic localization of 5-HT1A and preterminal axonal localization of 5-HT1B serotonin receptors in adult rat brain. J Comp Neurol 417:181-194.

Rice FL, Van der Loos, H (1977) Development of the barrels and barrel field in the somatosensory cortex of the mouse. J Comp Neurol 171:545-560.

Sari Y, Miquel MC, Brisorgueil MJ, Ruiz G, Doucet E, Hamon M, Verge D (1999) Cellular and subcellular localization of 5-hydroxytryptamine1B receptors in the rat central nervous system: immunocytochemical, autoradiographic and lesion studies. Neuroscience 88:899-915.

Saudou F, Amara DA, Dierich A, LeMeur M, Ramboz S, Segu L, Buhot MC, Hen R (1994) Enhanced aggressive behavior in mice lacking 5-HT1B receptor. Science 265:1875-1878.

Schlaggar BL, Fox K, O'Leary DD (1993) Postsynaptic control of plasticity in developing somatosensory cortex. Nature 364:623-626.

Senft SL, Woolsey TA (1991) Growth of thalamic afferents into mouse barrel cortex. Cereb Cortex 1:308-335.

Shatz CJ (1996) Emergence of order in visual system development. Proc Natl Acad Sci USA 93:602-608.

Shatz CJ, Stryker MP (1988) Prenatal tetrodotoxin infusion blocks segregation of retinogeniculate afferents. Science 242:87-89.

Stellwagen D, Shatz CJ, Feller MB (1999) Dynamics of retinal waves are controlled by cyclic AMP. Neuron 24:673-685.

Upton AL, Salichon N, Lebrand C, Ravary A, Blakely R, Seif I, Gaspar P (1999) Excess of serotonin (5-HT) alters the segregation of ipsilateral and contralateral retinal projections in monoamine oxidase A knock-out mice: possible role of 5-HT uptake in retinal ganglion cells during development. J Neurosci 19:7007-7024.

Vitalis T, Cases O, Callebert J, Launay JM, Price DJ, Seif I, Gaspar P (1998) Effects of monoamine oxidase A inhibition on barrel formation in the mouse somatosensory cortex: determination of a sensitive developmental period. J Comp Neurol 393:169-184.

Wong RO (1999) Retinal waves and visual system development. Annu Rev Neurosci 22:29-47.

Wong-Riley MT, Welt C (1980) Histochemical changes in cytochrome oxidase of cortical barrels after vibrissal removal in neonatal and adult mice. Proc Natl Acad Sci USA 77:2333-2337. 